\title{
Análisis comparativo de dos técnicas para el transporte vertical de la luz natural
}

\author{
Gerardo Ramírez González y Sebastián Orozco Muñoz
}

Afliliación: Tecnológico de Costa Rica, Costa Rica

Email: geramirez@itcr.ac.cr sorozco@itcr.ac.cr

Recibido: 22 de Junio del 2017

Aprobado: 13 de diciembre del 2017

\section{Gerardo Ramírez González.}

Máster Ingeniero, profesor a tiempo indefinido y exdirector de la Escuela de Arquitectura y Urbanismo del Tecnológico de Costa Rica. Investigador coordinador. Centro Académico de San José.

\section{Sebastián Orozco Muñoz.}

Máster Arquitecto, profesor a tiempo indefinido de la Escuela de Arquitectura y Urbanismo del Tecnológico de Costa Rica. Investigador secundario. Centro Académico de San José.

\begin{abstract}
Resumen
Este trabajo tiene como objetivo primordial comparar y establecer las relaciones de efectividad entre dos técnicas de diseño para el transporte vertical de la luz natural en el interior de las edificaciones. En primer lugar, se diseñó, construyó y utilizó un equipo experimental tipo concentrador domótico, con distribución a través de fibra óptica hacia un espacio interior sin ninguna iluminación natural tradicional, para monitorizar su efectividad por medio de un luxómetro digital y un recopilador de datos (Datalogger) de entrada múltiple. En segundo lugar, se monitorizó el rendimiento lumínico de un lucernario tradicional durante un periodo de seis meses. Finalmente, se realizó un estudio por medio de la Simulación Generada por Computadora (SGC), para establecer la relación entre las proporciones tridimensionales de los ductos de luz y la tasa de degradación de la iluminancia obtenida en el interior del espacio arquitectónico. En términos de resultados, el sistema de iluminación natural por fibra óptica (SINFO) no alcanza la efectividad lumínica del lucernario, sin embargo, presenta un rendimiento más uniforme y constante. La idea central es utilizar un criterio de comparación validado, tal como el factor de aprovechamiento de luz diurna (Daylight Factor) y otras métricas complementarias, para establecer una relación básica de efectividad entre ambas técnicas. Por último, se establecen recomendaciones de diseño con relación a la utilización de cada una de las técnicas.
\end{abstract}

Palabras clave: arquitectura de bajo consumo energético; factor de iluminación natural; fotometría; iluminación natural; simulación generada por computadora.

\section{Comparative analysis of two techniques for the vertical daylight transport}

\section{Abstract}

This research project has the main goal of establishing and comparing the effectiveness rate, between two specific design strategies for daylight vertical transport and distribution within buildings. To begin with, an experimental domotic sunlight concentrator, was designed, built, and installed, in order to transport daylight through an optic fiber bundle, into an interior room, without any natural light source. In this room, the concentrator's effectiveness was measured by means of a light sensor array attached to a multichannel datalogger. Simultaneously, the luminance performance of a traditional skylight shaft was also monitored during a six-month period. Finally, a computer generated simulation (CGS) analysis, was carried out, to establish the relationship between the three-dimensional proportions of light shafts, and the light loss rate experienced inside the architectural space.

In terms of results, the optic fiber daylight system didn't reach the skylight's effectiveness, however, it demonstrated a relatively more uniform and constant behavior. The central idea of this two-phased procedure, was to use a validated comparison criteria such as the Daylight Factor (DF\%) or Daylight Autonomy Factor (DA) and other complementary metrics, to determine a basic ratio between the lighting effectiveness of both techniques, and establish a series of brief recommendations about the optimum design of each system type.

Keywords: Computer Generated Simulation (CGS); daylighting; daylight autonomy factor; Low Energy Architecture (LEA); photometrics; raytracing daylight factor. 


\section{Introducción}

a temática de la optimización de la iluminación natural aplicada al diseño arquitectónico contempla un amplio catálogo de estudios y publicaciones a lo largo de casi 40 años de investigación, sin embargo, los conceptos de iluminación por medio de fibra óptica (FOL: Fiber Optic Lighting), y la simulación computacional (Daylight CGS) tienen menor antigüedad de abordaje académico y los primeros textos datan de finales de los años 90 (Advanced Daylighting Group, 1999).

Diversas instituciones y centros de investigación han producido artículos y proyectos sobre la temática pero todos fuera de la franja de clima tropical. Entre los más relevantes se encuentran el Lighting Research Center (LRC) del Rensselaer Polytechnic Institute de Nueva York, Journal of Industrial Technology, el Istituto Nazionale Di Ottica Applicata, la Universidad Tecnológica de Shangdon y la empresa norteamericana NoUVIR.

En el contexto latitudinal de los trópicos, donde se encuentra Costa Rica, el consumo energético de los edificios atiende en gran medida la necesidad de iluminar artificialmente un alto porcentaje de espacios internos en periodos de horas diurnas, durante las cuales se desaprovecha el enorme potencial energético de la iluminación natural. Además de este, existe también el aspecto del consumo energético por concepto de climatización artificial del espacio interno, asociado a un mal manejo de cargas térmicas tanto internas como externas, sin embargo, en el contexto mencionado, este no suele ser el problema prioritario.

En Costa Rica, el problema del desaprovechamiento de la luz natural se combina con la actual tendencia a la verticalidad de las tipologías constructivas tanto comerciales como residenciales. Si bien esta es una tendencia acertada y necesaria para aumentar la compacidad de los asentamientos urbanos, el mal manejo y el pobre planteamiento de la iluminación natural dentro de una estratificación vertical de múltiples niveles trae como resultado un consumo energético innecesariamente exacerbado. Este suele ser el resultado de una formación profesional en las áreas de la Arquitectura y la Ingeniería relativamente carente de conceptos bioclimáticos claros, así como de las herramientas necesarias para desarrollarlos. En este punto es donde surge este trabajo, como un esfuerzo por profundizar en el alcance de la temática mencionada, al tiempo que complementa la formación de futuros profesionales desde sus etapas más tempranas.

La idea fundamental fue desarrollar un ejercicio híbrido de experimentación tangible, con equipos físicos, en combinación con la experimentación virtual realizada por medio de modelos de simulación computacional. La fase experimental del estudio requirió del diseño y construcción de múltiples equipos de concentración, distribución y medición, dado que en la actualidad no existe ningún motor de cálculo capaz de simular el comportamiento de la luz natural al ser transportada a través de la fibra óptica. Por su parte, la fase de simulación computacional se llevará a cabo mediante los motores de cálculo de libre distribución RADIANCE (Laboratorio Nacional de la Universidad de Lawrence Berkeley, LBNL por sus siglas en inglés) y DAYSIM (HU. NRCC. FISES), dado que son las herramientas fotométricas validadas de mayor desarrollo en el medio a nivel mundial.

Durante el proceso se calculó también la desviación estándar de los datos para hacer estimaciones de varianza entre los valores, con el objetivo específico de analizar la uniformidad de la iluminancia obtenida. Este es el mejor abordaje para el tratamiento de datos con orígenes tan distintos como los mencionados. Además, se seleccionó el modelo debido a que permite la calibración de la herramienta de simulación con el fin de realizar proyecciones predictivas más precisas.

La consolidación de esta información sobre un gráfico o tabla cuantitativa permitirá aportarle al diseñador arquitectónico una guía ágil para el dimensionamiento de estos sistemas y para la comprensión conceptual del comportamiento de la luz natural. 


\section{Sistema de Monitorización y almacenamiento de datos}

En la Fig.1 y Fig.2 se aprecia la situación nacional de Costa Rica en función de la irradiación global horizontal a escala continental y el brillo solar. Es notorio que el país se encuentra en una zona de intensidad media, con valores anuales en el rango de los 1700-1800 Kwh/m². (Remund \& Müller, 2011)

Yearly sum of Global Horizontal Irradiation (GHI)

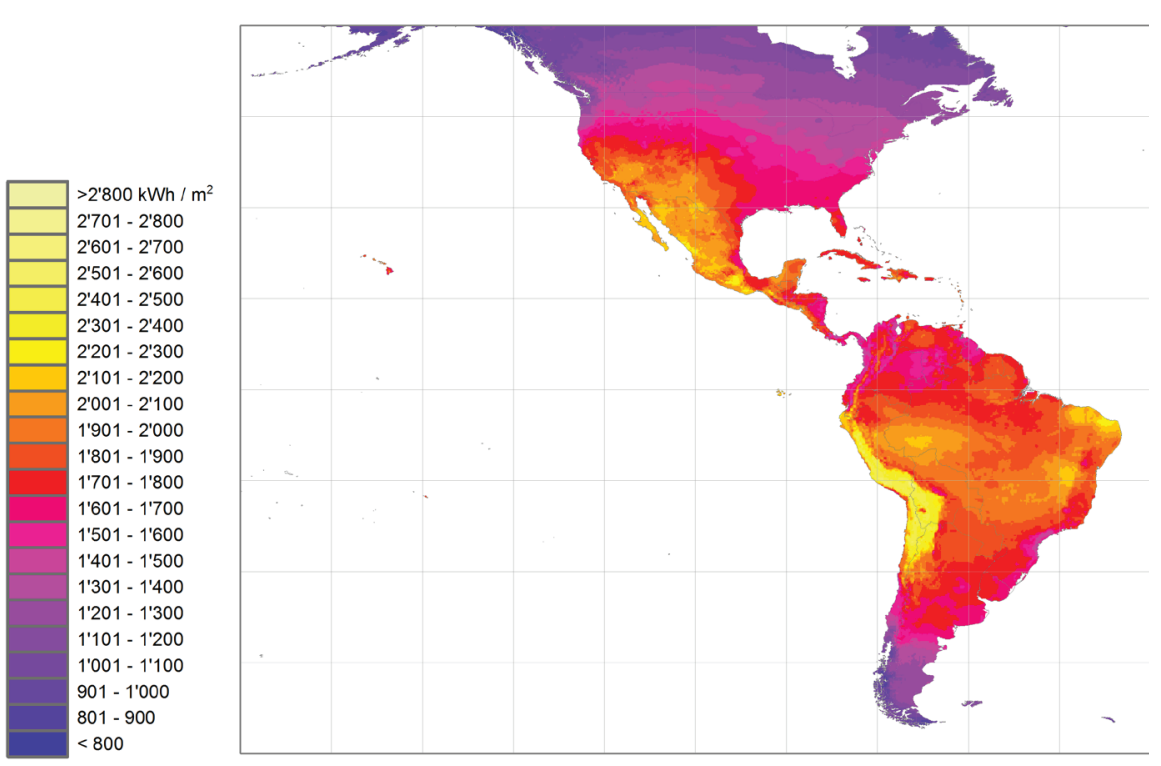

Source: Meteonorm 7.1 .5 (www.meteonorm.com); uncertainty $8 \%$ Period: 1991 - 2010; grid cell size: $0.125^{\circ}$

\section{A \\ Figuras 1. Derecha. Sumatoria anual de irradiación global horizontal.}

Figura 2. Izquierda. Mapa de duración del brillo solar.

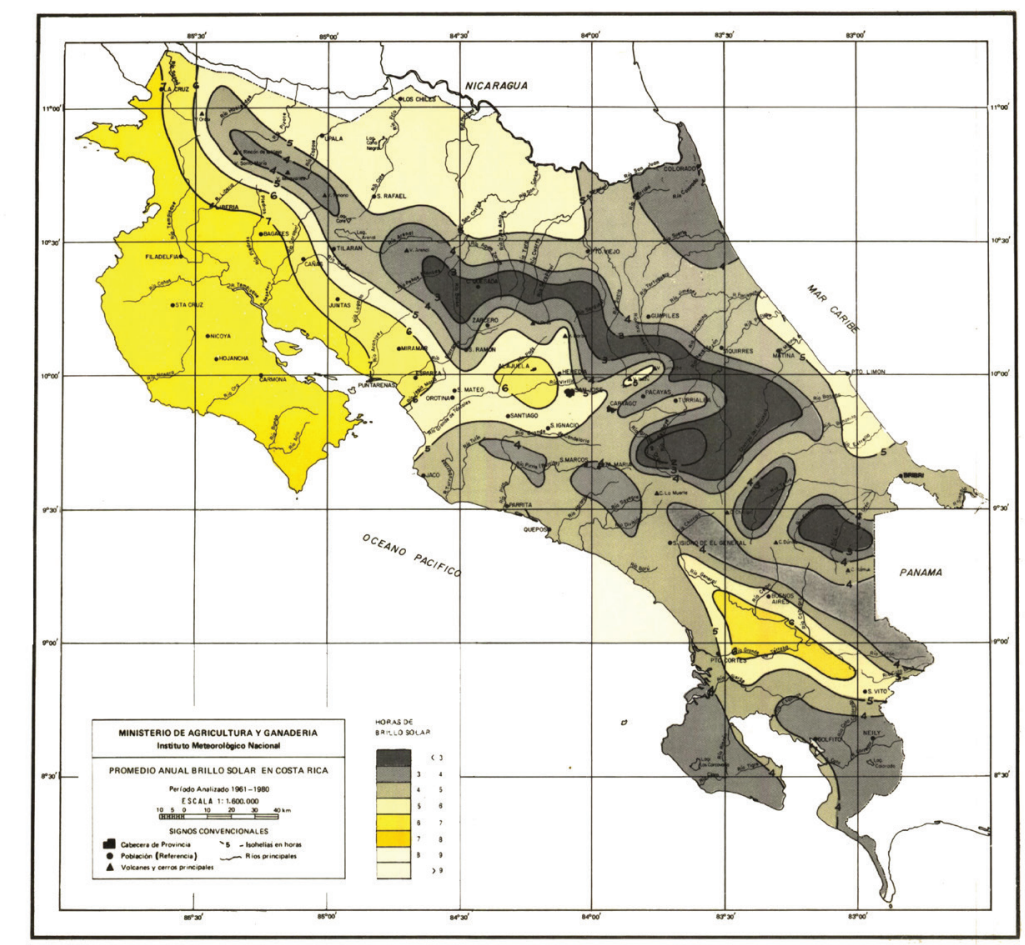

En consideración a lo anterior y a las características físicas del Centro Académico de San José (CASJ) del Tecnológico de Costa Rica (TEC), el montaje del sistema de monitorización se definió en función de los espacios a ser analizados. Estos a su vez están asociados a un tipo de condición de iluminación específica, según se enlista a continuación:

Lucernario: Transporte vertical directo de luz natural, a través de una lámina translúcida en cubierta y un ducto rectangular.

Laboratorio: Transporte indirecto de luz natural, a través de un sistema de iluminación natural por fibra óptica (SINFO).

Cubierta: Referencia de iluminancia horizontal global sobre un plano de captación común para los dos espacios mencionados.

La Fig.3 y Fig.4 ilustran la distribución espacial de los espacios mencionados.
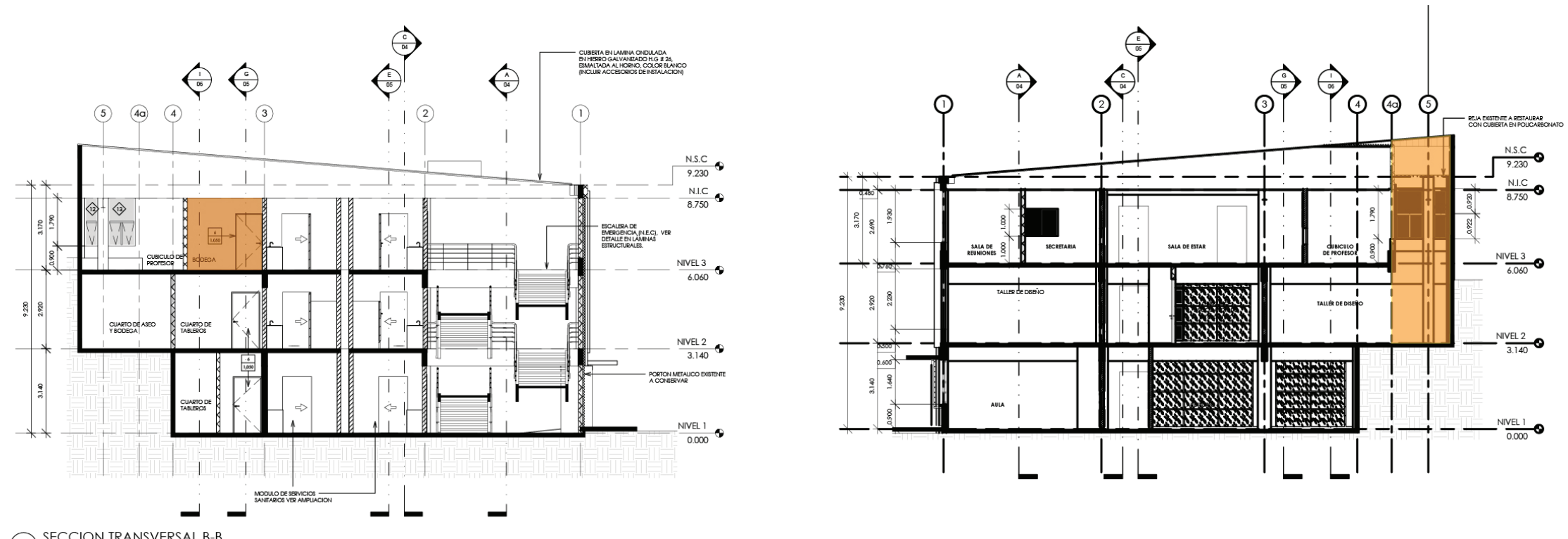

(F) $\frac{\text { SECCION TRANSVERSAL F-F }}{\text { Ecil: } 15}$

El modelo analítico del lucernario, así como fotografías del espacio, se presentan en la Fig.5, Fig.6 y Fig.7

Figura 3. Izquierda. Sección ilustrativa del edificio SJ-2, laboratorio.

Figura 4. Derecha. Sección ilustrativa del edificio SJ-2, lucernario
El modelo analítico del laboratorio, así como fotografías del espacio, se muestran en la Fig. 8, Fig. 9 y Fig. 10 

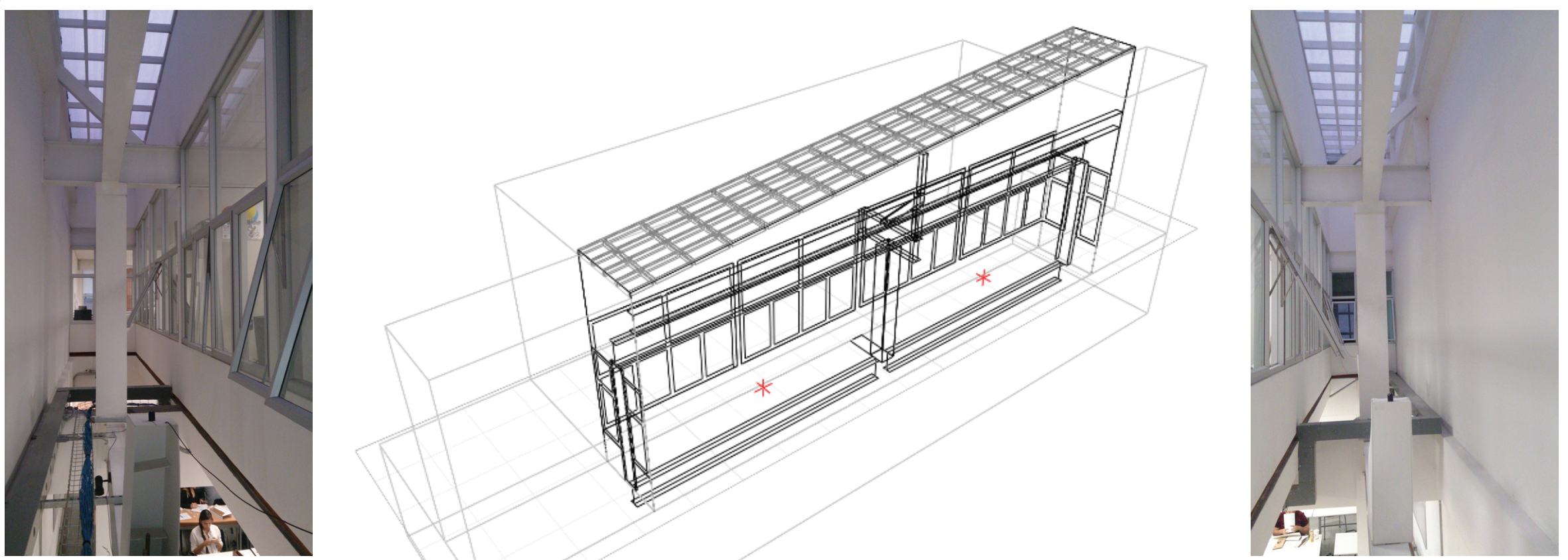

A

Figura 5. Izquierda. Fotografía del lucernario.

Figura 6. Central. Modelo analítico del lucernario elaborado en Autodesk Ecotect 2011

Figura 7. Derecha. Fotografía del lucernario.

Figura 8. Izquierda. Modelo analítico del laboratorio elaborado en Autodesk Ecotect 2011.

Figuras 9 y 10. Central y Derecha. Fotografías del laboratorio.

Figura 11. Fotografía de la cubierta del edificio SJ-2.
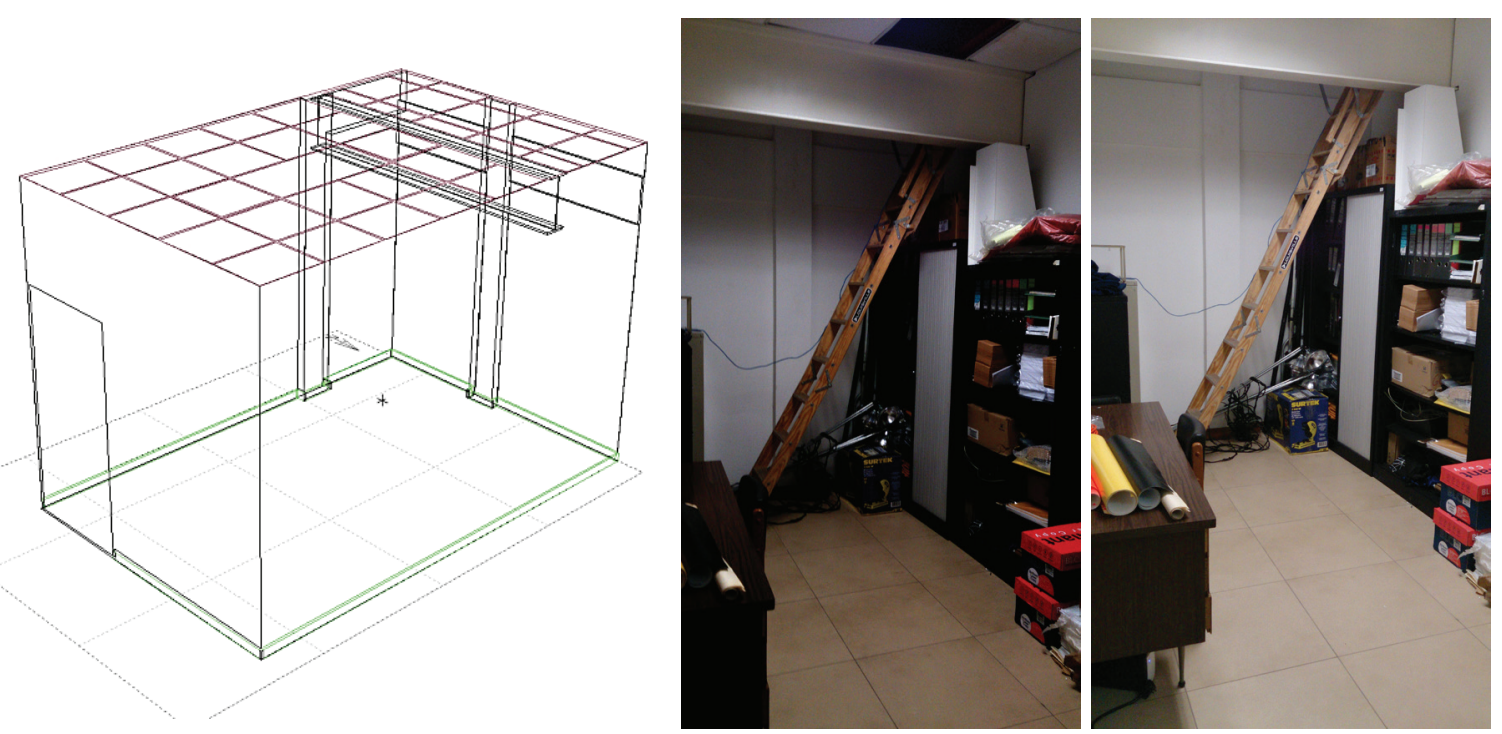

La intensidad de la iluminancia exterior sobre un plano horizontal fue medida a nivel de cubierta. Esta tiene dos direcciones de pendiente al 10\%, con una línea divisoria en sentido diagonal Noroeste-Sureste (Ver Fig. 11).

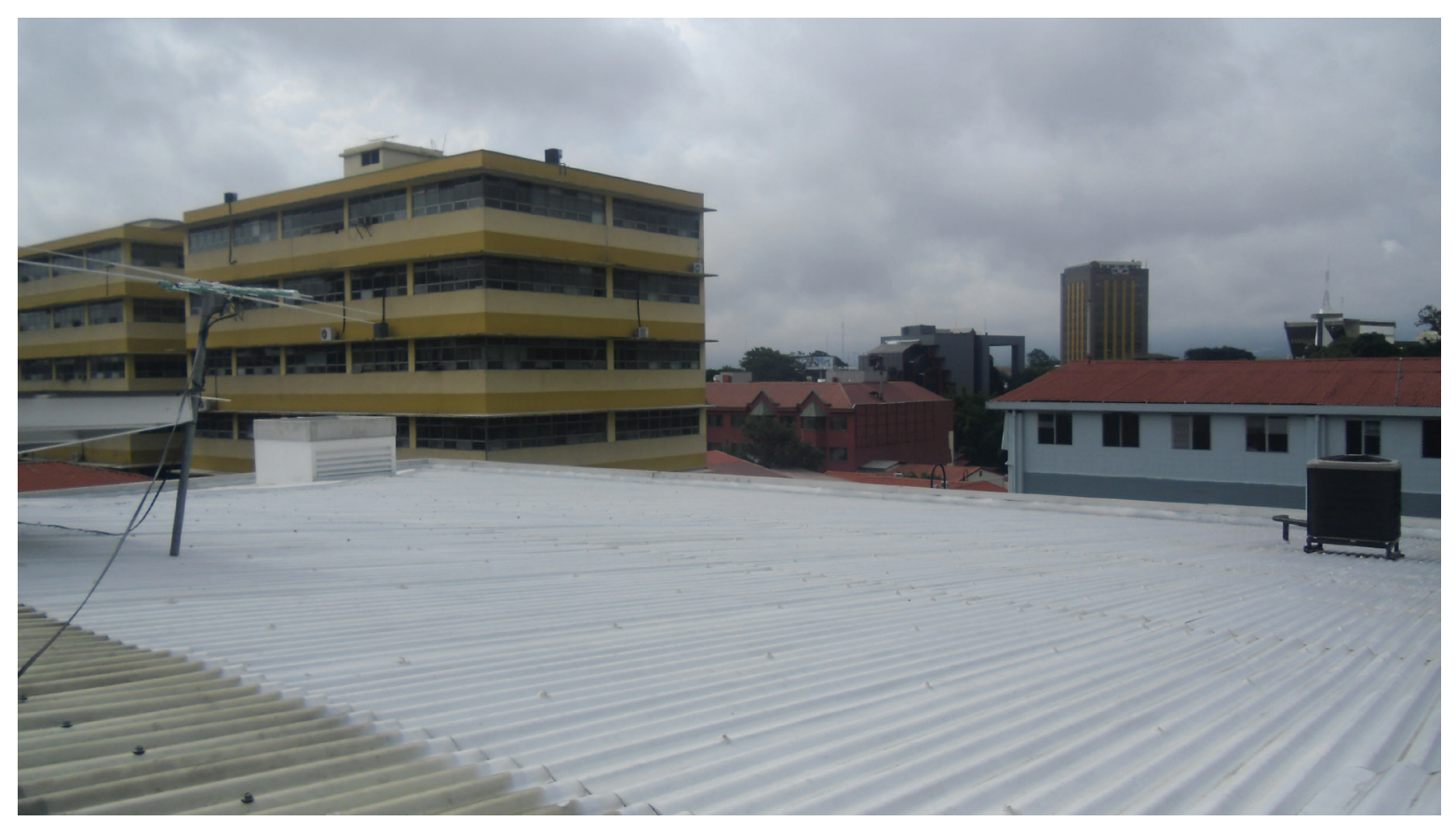

Las mediciones del rendimiento de los tres sistemas, tanto lucernario como SINFO, y el de rewwwferencia en cubierta, fueron monitorizadas y almacenadas para su posterior análisis en un sistema de Datalogger HOBO modelo U30, con entrada múltiple de cuatro sensores.

Asimismo, se utilizó una estación meteorológica DAVIS modelo Vantage Pro 2, como control cruzado, específicamente para la corroboración de los datos de radiación solar horizontal exterior. 
Figura 12. Equipos de recopilación y almacenamiento de datos (Datalogger Hobo U-30).

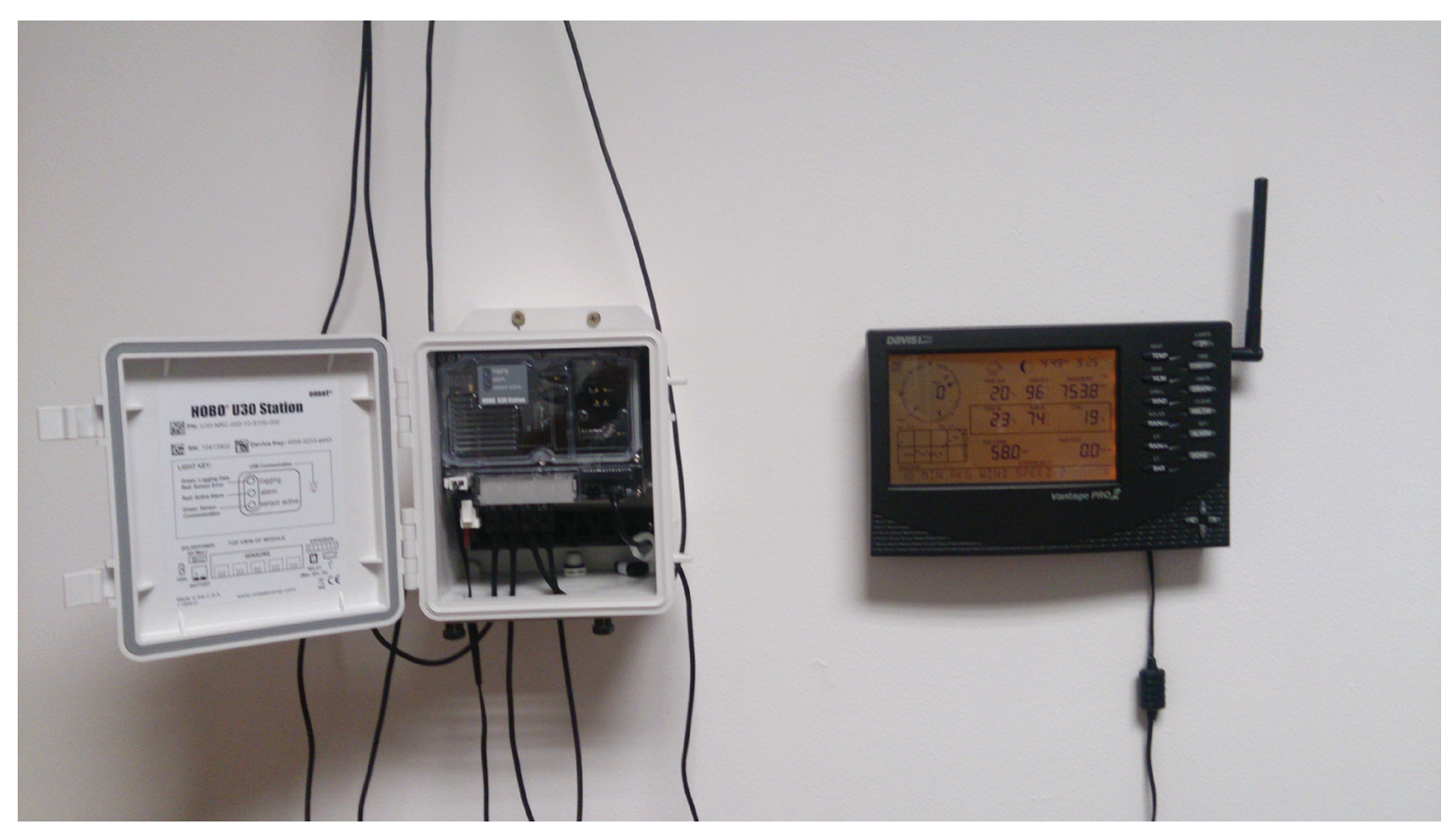

\section{Evaluación del rendimiento lumínico del lucernario}

\section{Registros de irradiación}

La primera serie de datos a recolectar y consolidar para poder determinar el rendimiento de aprovechamiento lumínico del lucernario fue la irradiación global horizontal incidente sobre la cubierta del edificio SJ-2, con frecuencia de muestreo cada 10 minutos y durante un periodo semestral (un arco solar completo). La intención es utilizar esta serie de datos en dos maneras, primero como referencia de cálculo para la determinación del factor de aprovechamiento de luz (Daylight Factor o DF\%); y en segundo lugar como un control, durante el análisis de tendencias y desviación estándar de las mediciones interiores.

La Fig.13 y Fig.15 muestran los gráficos de análisis de los registros de irradiación externa.
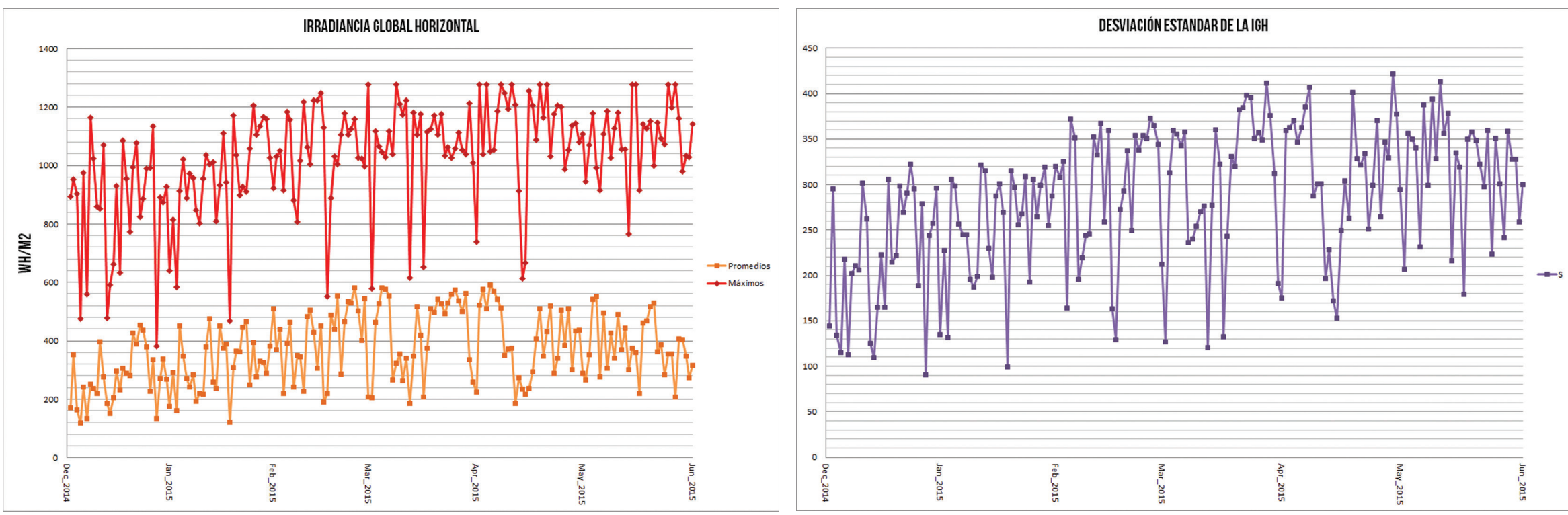

Los gráficos anteriores son una clara muestra de la enorme variabilidad en la disponibilidad del recurso solar durante el periodo de estudio. Tanto el comportamiento errático de la irradiación como las grandes diferencias en la desviación estándar de los datos evidencian la importancia que la cobertura nubosa ejerce sobre las posibilidades de cosecha de la irradiación solar. Este componente es crítico por cuanto, como se expondrá más adelante, los lentes utilizados en el concentrador del SINFO funcionan casi exclusivamente con haces de irradiación solar directa. 

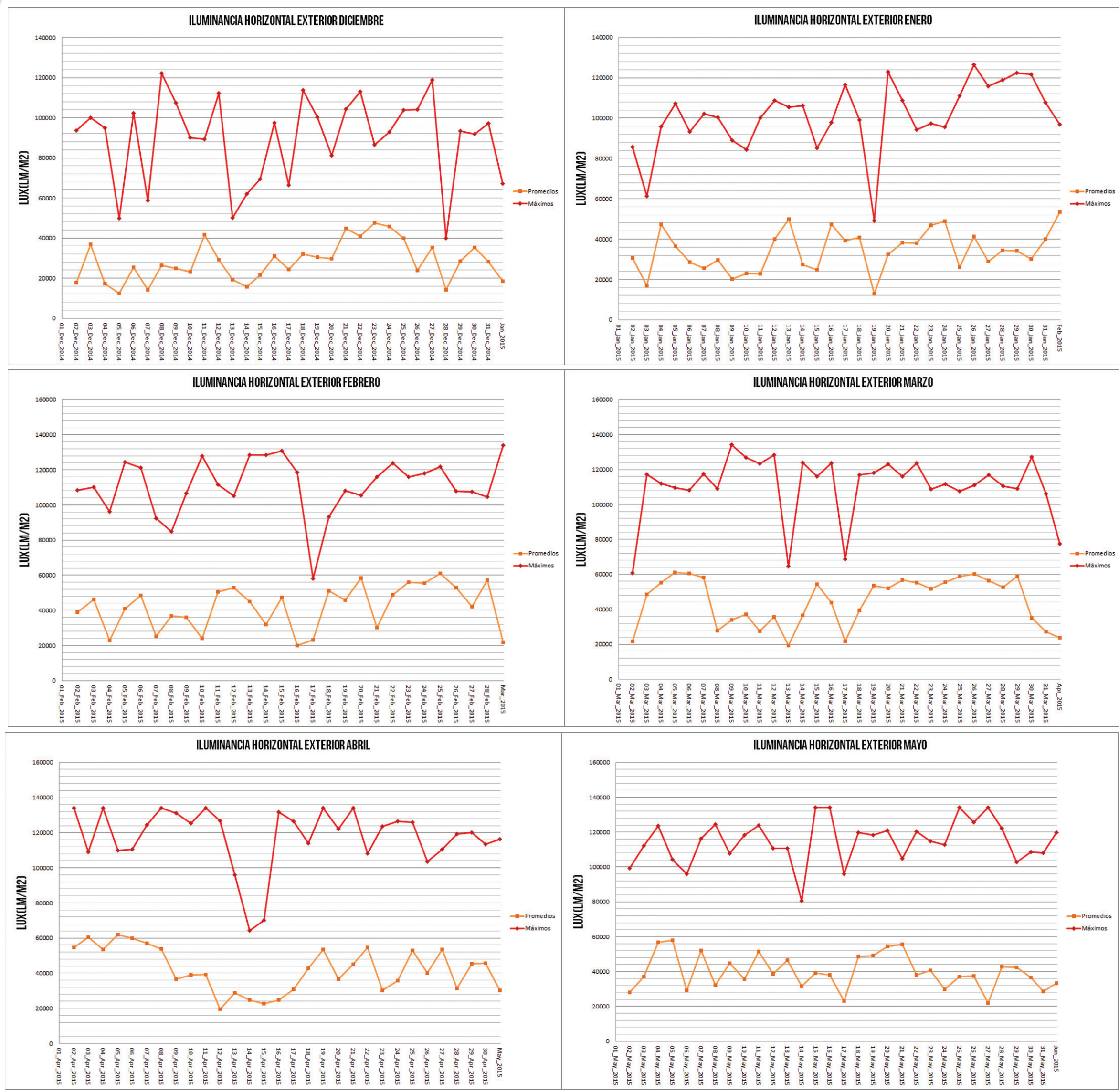

A

Figura $15,16,17,18,19$ y 20 . Valores mensuales de iluminancia exterior. Frecuencia según promedios diarios.

\section{Registros en el exterior}

\section{Iluminancia exterior}

A partir de estas mediciones, fue posible determinar datos mensuales de iluminancia exterior, los cuales se muestran en la Fig.15, Fig.16. Fig.17, Fig.18, Fig.19 y Fig.20 correspondientes a los meses de diciembre a mayo.
Figura 21. Ubicación de sensores dentro del lucernario.

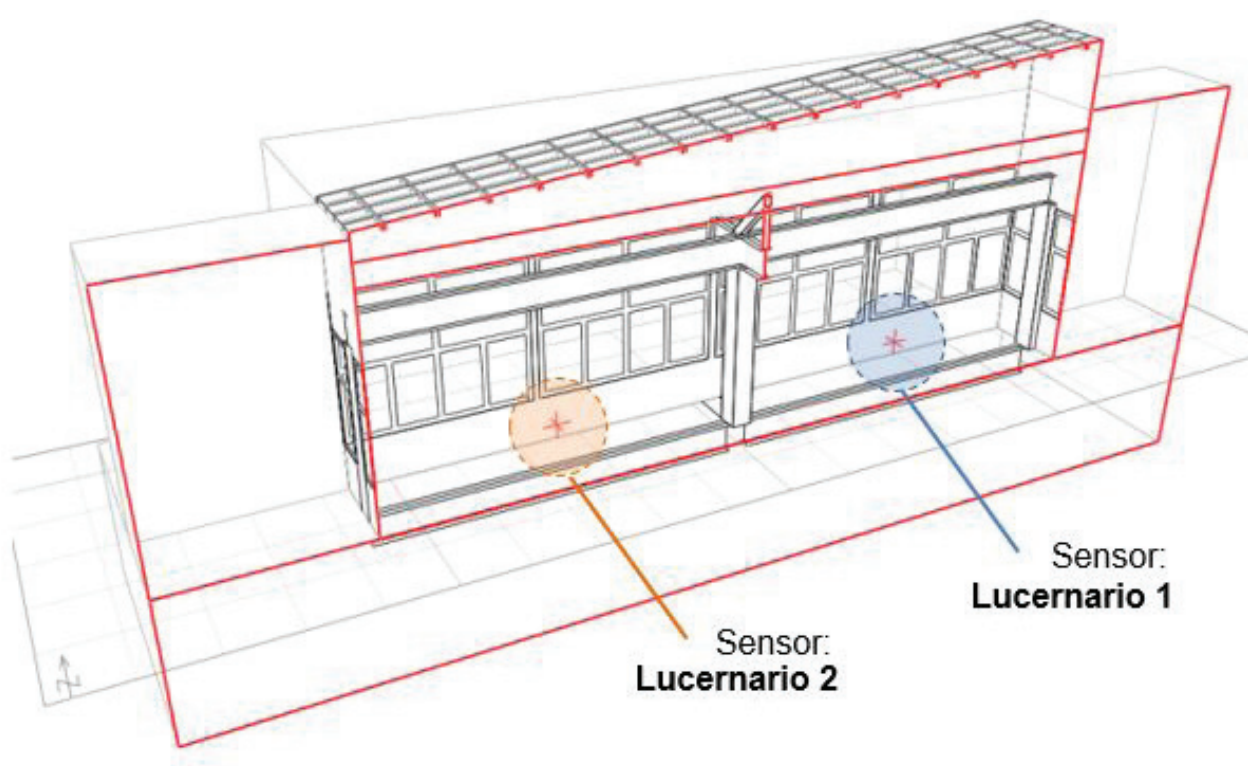



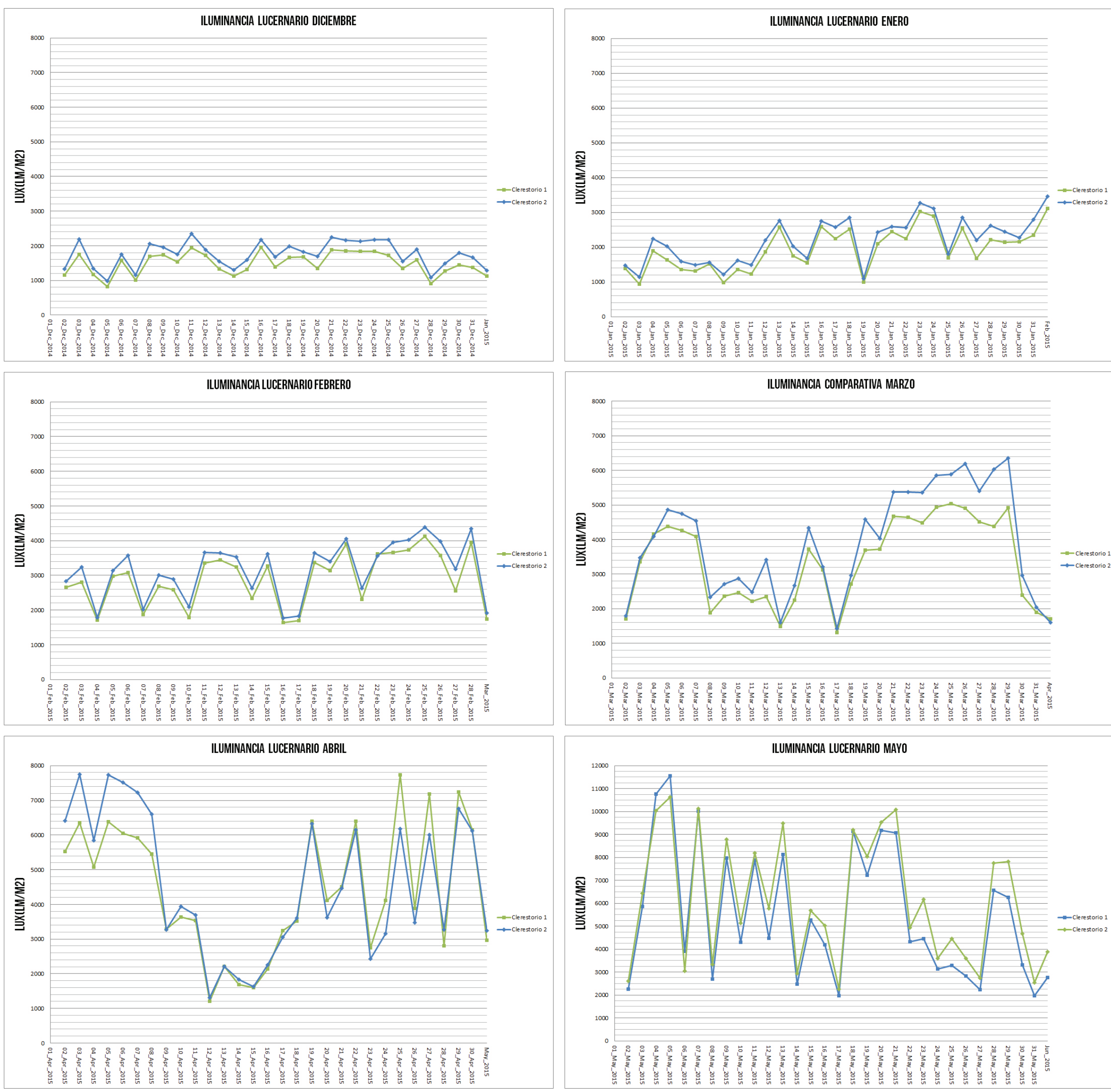

A

Figuras $22,23,24,25,26$ y 27 . Valores mensuales de iluminancia lucernario.

\section{Registros en el interior}

Las mediciones en el espacio interno se describen en función de dos métricas básicas: niveles de iluminancia y factor de aprovechamiento.

\section{lluminancia interior}

De igual manera, se recolectaron y analizaron datos provenientes de dos sensores independientes colocados simétricamente dentro del espacio interno del lucernario, como se muestra en la Fig. 21.

La diferencia en la posición de estos dos sensores se ve reflejada como un desfase horario en la intensidad de las lecturas, mostrando mayores intensidades en el sensor 1 durante las tardes y en el sensor 2 durante las mañanas. Los gráficos de la Fig.22, Fig.23, Fig.24, Fig. 25, Fig.26 y Fig.27 correspondientes a estas series de datos. La escala ha sido configurada con un valor máximo de $8000 \mathrm{Lx}$.

De los gráficos anteriores se desprenden dos conclusiones parciales. Inicialmente es posible apreciar el efecto de la variabilidad externa mencionado previamente. Las lecturas de ambos sensores tienden a ser altamente variables, y esta variabilidad tiende a aumentar conforme el recorrido solar se acerca más a la posición cenital, durante el 
En segunda instancia, surge la visibilidad de una pequeña diferencia entre la intensidad de las lecturas del sensor 1 (este) vs el sensor 2 (oeste) con valores consistentemente mayores en el sensor 2. Este comportamiento refleja una mayor disponibilidad de recurso solar lumínico durante las horas de la mañana, cuando este sensor recibe una mayor cantidad de radiación, tanto directa como reflejada.

\section{Factor de aprovechamiento (Daylight Factor)}

El Dr. Cristoph F. Reinhart, de la Escuela de Diseño de Harvard (Graduate School of Design), define el DF\% como el ratio de iluminancia interna en un punto específico, con relación a la iluminancia horizontal exterior, bajo las condiciones de cielo nublado de la CIE (Lam \& Li, 1996). Se trata, por lo tanto, de un parámetro de amplia difusión y utilización analítica, gracias a su comprensión intuitiva y su facilidad de cálculo: DF = $E_{v}$ int/E $E_{v}$ ext
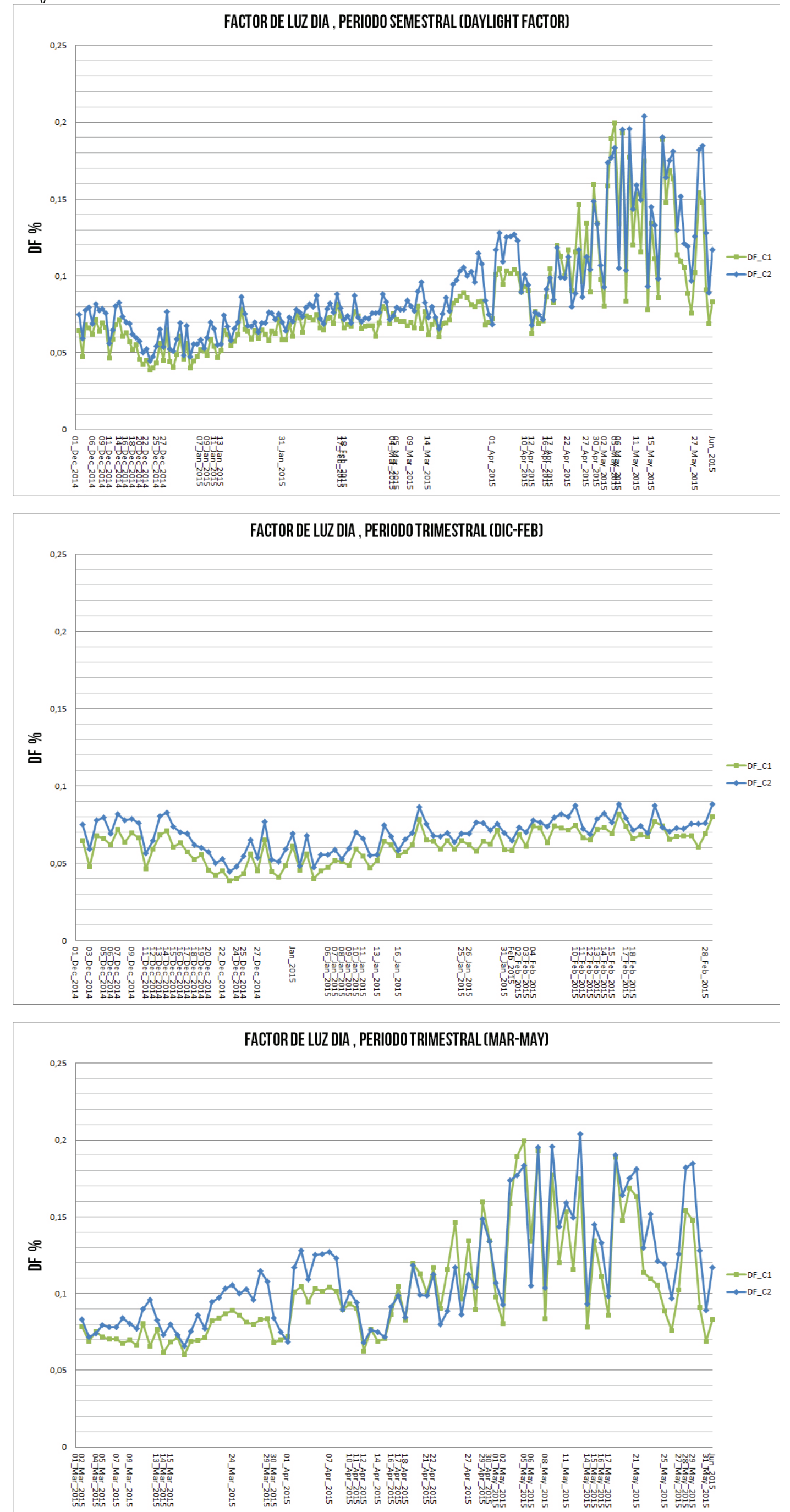
Figura 31. Tabla de recomendación de iluminancia en espacios de oficina_CIBSE.
Los niveles de DF\% obtenidos por los sensores 1 y 2 bajo el lucernario del edificio SJ-2 se muestran en la Fig. 28, Fig, 29 y Fig.30, utilizando una escala con valor máximo de $25 \%$.

\section{Factor de autonomía lumínica DA}

La principal limitación del parámetro del DF\% radica en que desprecia las características climáticas y geográficas específicas del entorno en el que se ubica el edificio estudiado. Por esta razón, se hace preciso el uso de un parámetro más aplicable a la especificidad del caso de estudio.

El mismo Reinhart reconoce la necesidad de métricas "clima-dependientes", durante el desarrollo del motor de cálculo para simulación DAYSIM (Lam \& Li, 1996). Entre otras métricas desarrolladas por su equipo, se encuentra el factor de autonomía lumínica (DA), que se define como el porcentaje de horas ocupadas al año durante las cuales un valor mínimo de iluminancia puede satisfacerse sin usar fuentes artificiales. (Nabil, \& Mardaljevic, 2005)

Con base en esto, se debe definir un valor mínimo como requerimiento crítico, contra el cual se compararán los valores obtenidos por los sensores, y poder determinar el DA.

\begin{tabular}{c|c} 
Space & Recommended maintained illuminance \\
\hline Open plan office - mainly screen based work & $300 \mathrm{~lx}$ \\
\hline Open plan office - mainly paper based work & $500 \mathrm{~lx}$ \\
\hline Deep plan core area (more than 6m from window) & $500 \mathrm{~lx}$ \\
\hline Cellular office - mainly screen based work & $300 \mathrm{~lx}$ \\
\hline Cellular office - mainly paper based work & $500 \mathrm{~lx}$ \\
\hline Graphics work stations & $300 \mathrm{~lx}$ \\
\hline Dealing rooms & $300-500 \mathrm{~lx}$ \\
\hline Executive offices & $300-500 \mathrm{~lx}$ \\
\hline
\end{tabular}

Para este fin, se ha tomado como referencia la escala de iluminación recomendada del manual de iluminación de la Sociedad de Luz e lluminación SLL, una división del CIBSE británico (Boyce \& Raynham, 2009), fundamentalmente por su nivel de especificidad. (Ver Fig. 31)

Es posible apreciar que la mayoría de valores recomendados oscila entre los 300 y 500 luxes, dependiendo casi siempre del tipo de medio (papel o pantalla) sobre el cual se está proyectado trabajar. Así las cosas, se ha definido un valor de 400Lx como umbral mínimo de satisfacción para el análisis del parámetro DA, en adelante DA400.

\section{El sistema de iluminación natural por fibra óptica (SINFO)}

La segunda técnica estudiada constituye un acercamiento tecnológico aplicado basado en sistemas preexistentes, pero adaptado al contexto solar de la franja tropical.

En sí, el SINFO representa una posibilidad de utilizar la energía lumínica del sol como se maneja y conduce la energía eléctrica, a través de instalaciones de cables y tuberías.

\section{Diseño del SINFO}

En esencia, la tipología del colector a diseñar corresponde a un colector domótico de doble eje, con concentradores ópticos fresnel (André \& Schade, 2002).

El equipo de diseño industrial separó el sistema en los siguientes componentes:

- Base de anclaje

- Concentrador

- Líneas de conducción

- Luminaria. 
Figura 32. Diagrama de relación entre componentes SINFO.
Figura 33. Izquierda. Ilustración-descriptiva-delente-Fresnel.

Figura 34. Derecha. llustración descriptiva de lente Fresnel.

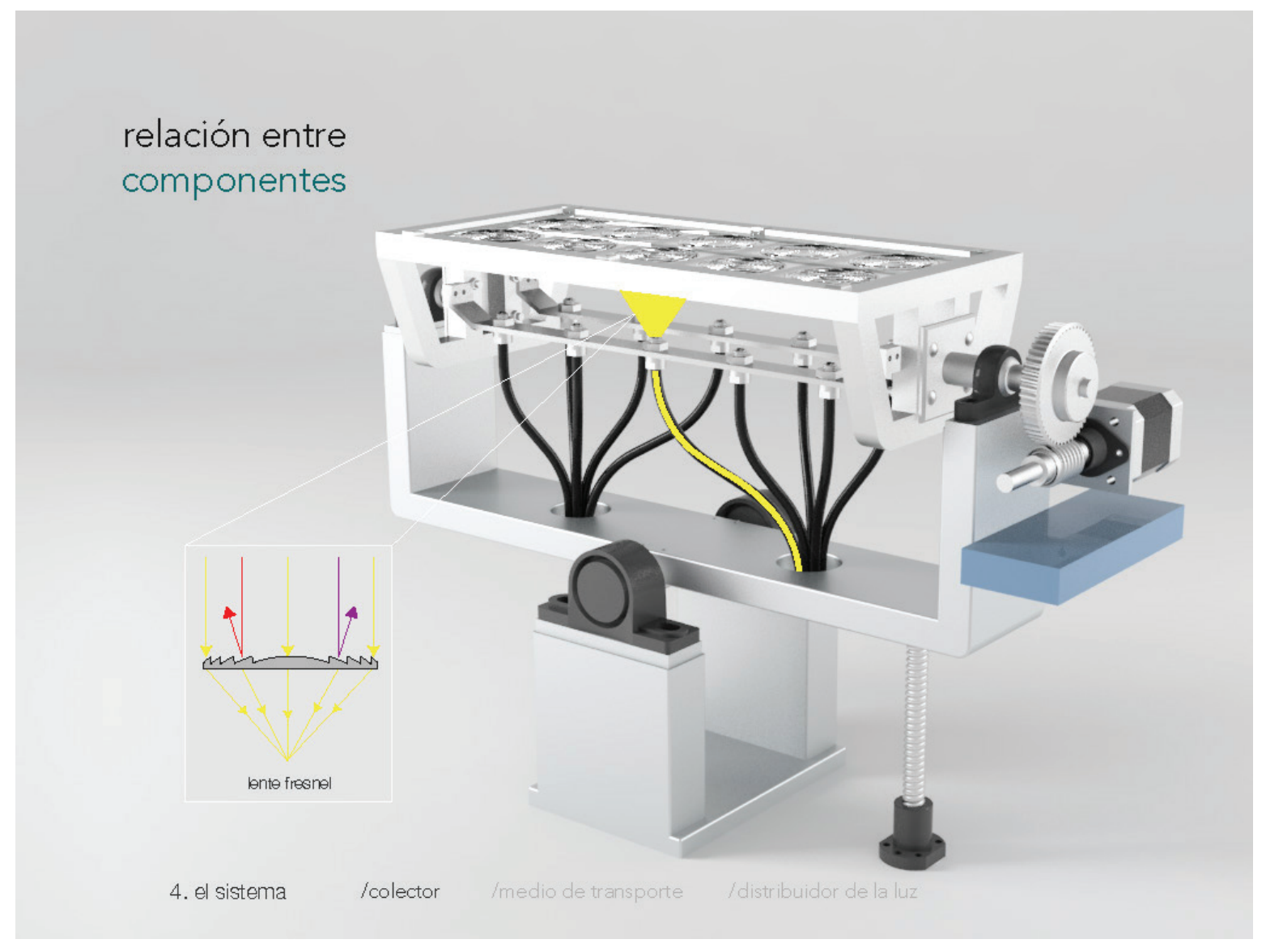

Cabe destacar que el componente crítico, por la incorporación de un sistema de movimiento y la sofisticación de sus componentes, fue el concentrador. De igual manera, el componente de luminaria, si bien fue diseñado, no constituye un elemento determinante en términos del alcance de esta investigación, por lo que fue sustituido por luminarias de tipo NOUVIR LBPR.

Como se mencionó previamente, el concentrador es un componente de gran complejidad, con múltiples subsistemas internos:

1- $\quad$ Filtro UV/IR y lentes Fresnel: En este aspecto, el medio de separación del espectro radiométrico es el uso de un filtro IR/UV fabricado a medida por la empresa ROSCO-USA. Este consiste de un espejo de calor dicroico, con una cobertura multicapa capaz de bloquear un $98 \%$ de la radiación UV y hasta un $85 \%$ de la radiación IR.
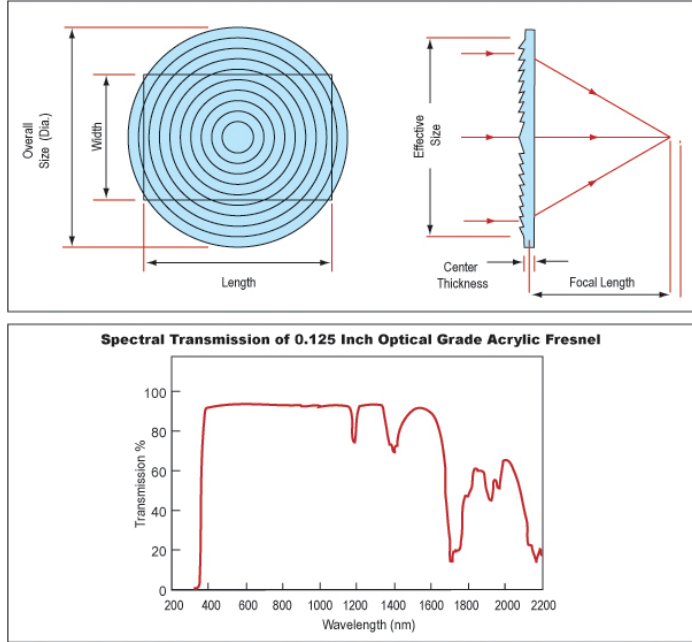

2- $\quad$ Motores y sistema de movimiento: Este componente comprende una serie de piezas móviles de crucial importancia para el seguimiento solar sobre dos ejes (diario y anual).

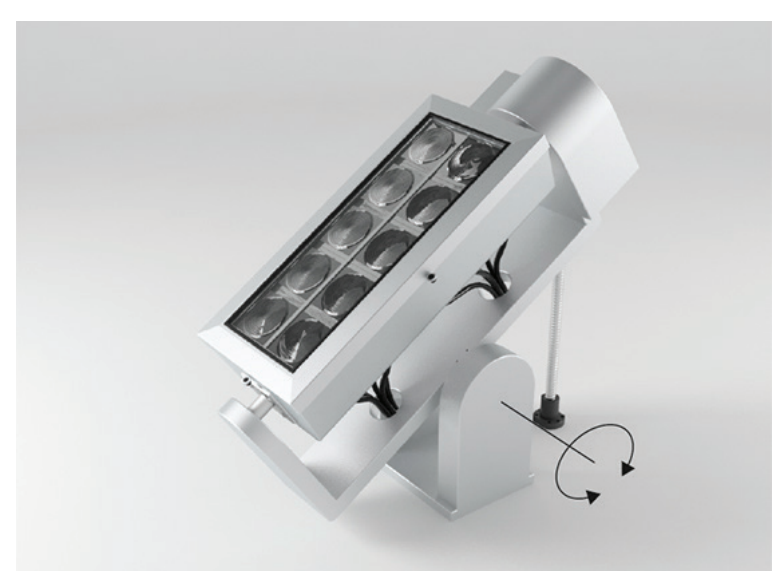

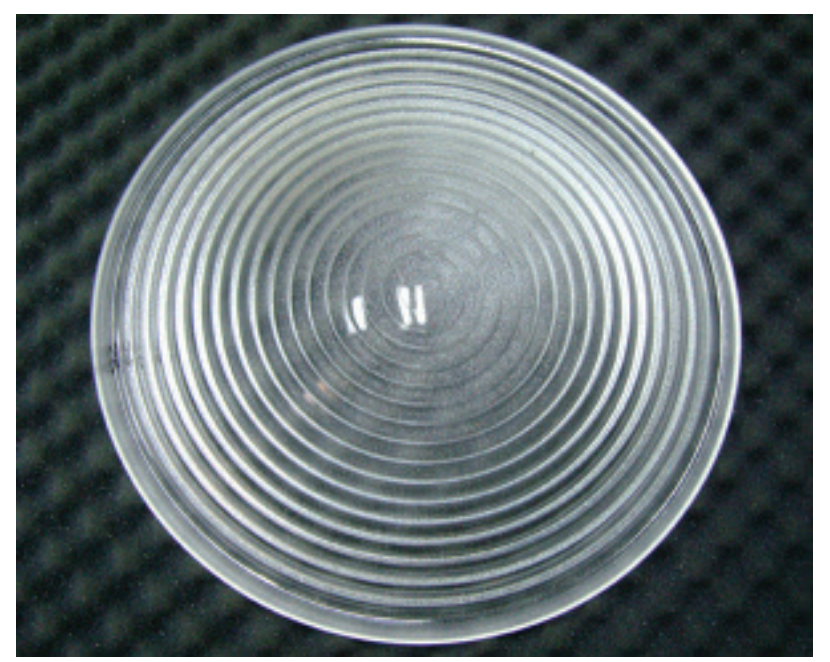

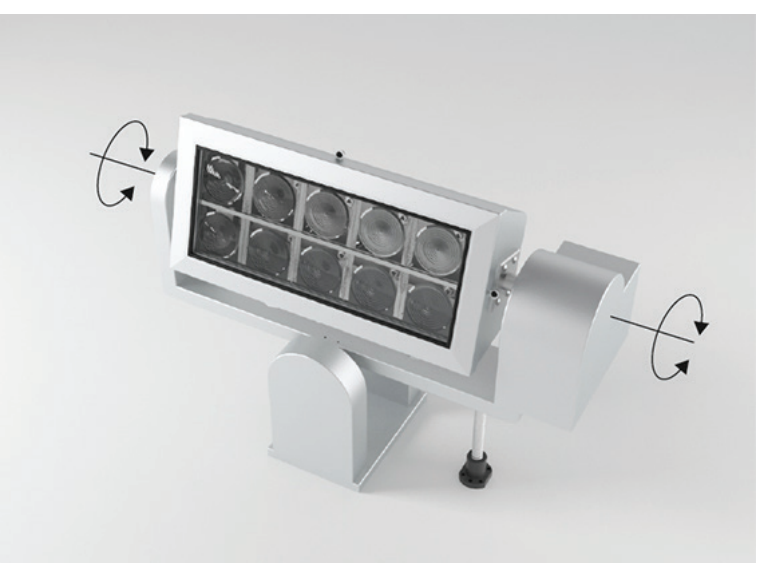


Figura 36. Izquierda. Motor de control de eje vertical SINFO.

Figura 37. Derecha. Sistemas de pivote y movimiento horizontal del SINFO.

Figura 38. Izquierda. Instalación de fibras en el SINFO.

Figura 39. Derecha. Controlador Arduino One dentro del SINFO.

Figura 40. Izquierda. Colocación y ajuste de lentes Fresnel.

Figura 41. Derecha. Filtro UV-IR sobre lentes Fresnel. $>$
Para ello, se utilizaron dos motores bipolares a pasos del fabricante Applied Motion conectados con un ensamble de engranajes helicoidales y una gata mecánica respectivamente.

\section{Construcción del SINFO}

\section{Chasis y sistema de movimiento}

Para este componente se elaboró un primer prototipo de movimiento unidireccional sobre el eje este-oeste de rotación solar diaria.

El modelo final con movimiento biaxial fue elaborado a partir de la patente Taiwan Patent M361043, del Dr. José Luis León Salazar, de la Escuela de Ciencias e Ingeniería de los Materiales (ECIM).
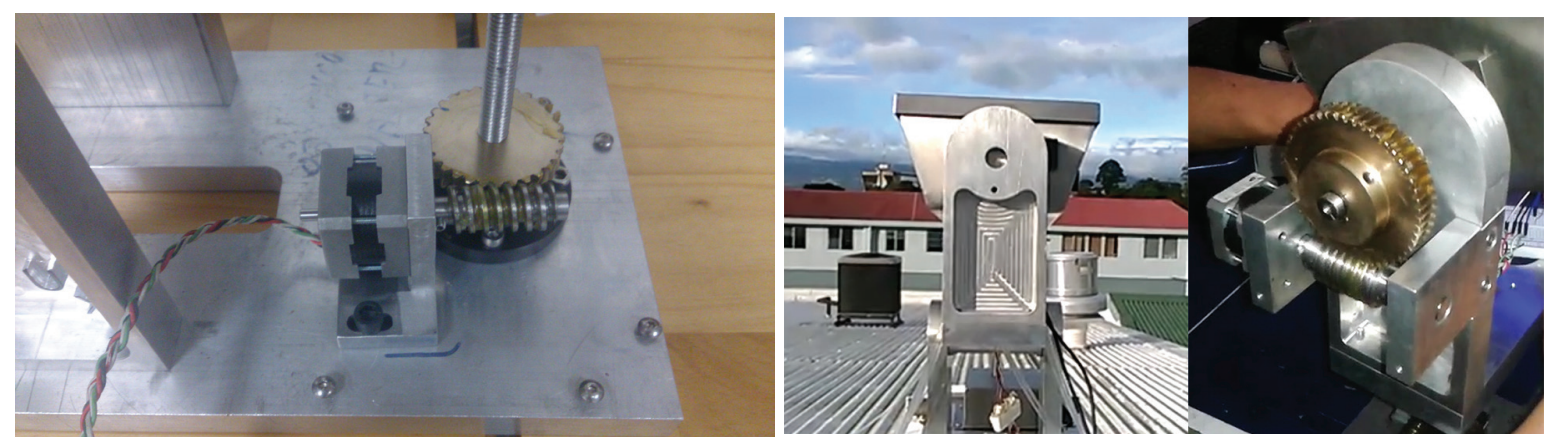

\section{Sistema de control y seguimiento solar}

Una de las principales dificultades que se encontraron durante el proceso de materialización del SINFO es el "cerebro" domótico del concentrador solar. En este sentido, se descubrió que el rango de movimiento necesario para el seguimiento solar dentro de la franja latitudinal tropical es sumamente amplio para una correcta compatibilidad con la rigidez propia de la fibra óptica seleccionada. (Miller, 2013)

Las placas y los drivers de los motores se colocaron en el interior de la carcasa del concentrador, como se muestra en la Fig. 38 y Fig.39.
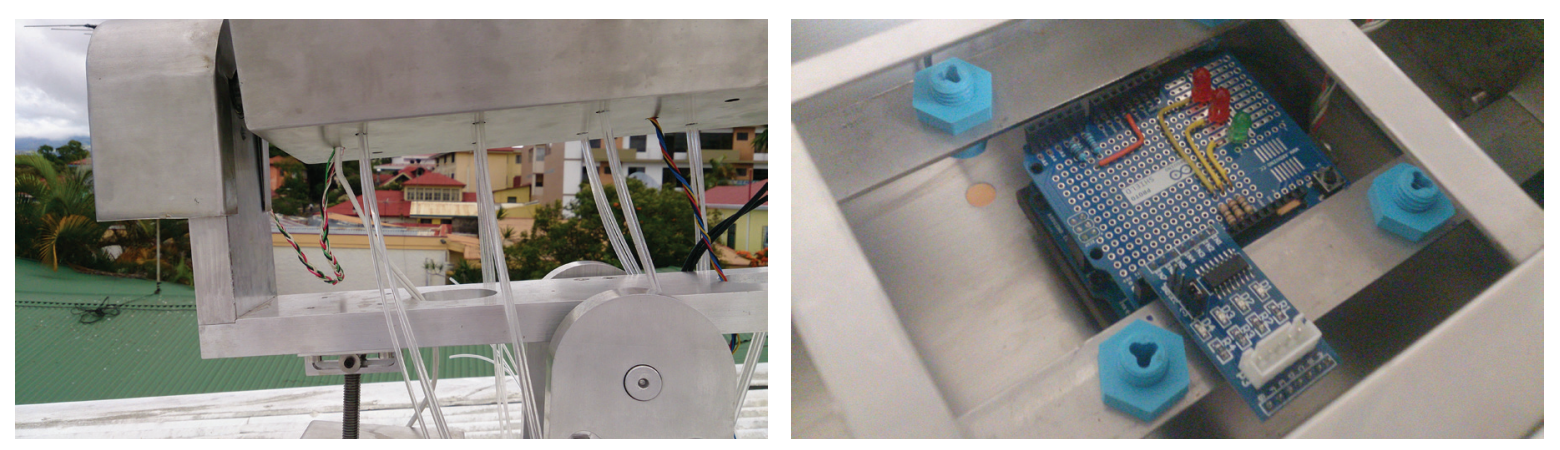

\section{Componentes ópticos de acumulación y transporte de la luz}

\section{Lentes}

Los diez lentes Fresnel se colocaron sobre dos marcos reticulares metálicos, en una configuración de tipo emparedado.

\section{Filtro}

El filtro UV/IR fue encargado a medida, de manera tal que lograse calzar exactamente en el área determinada por los lentes.
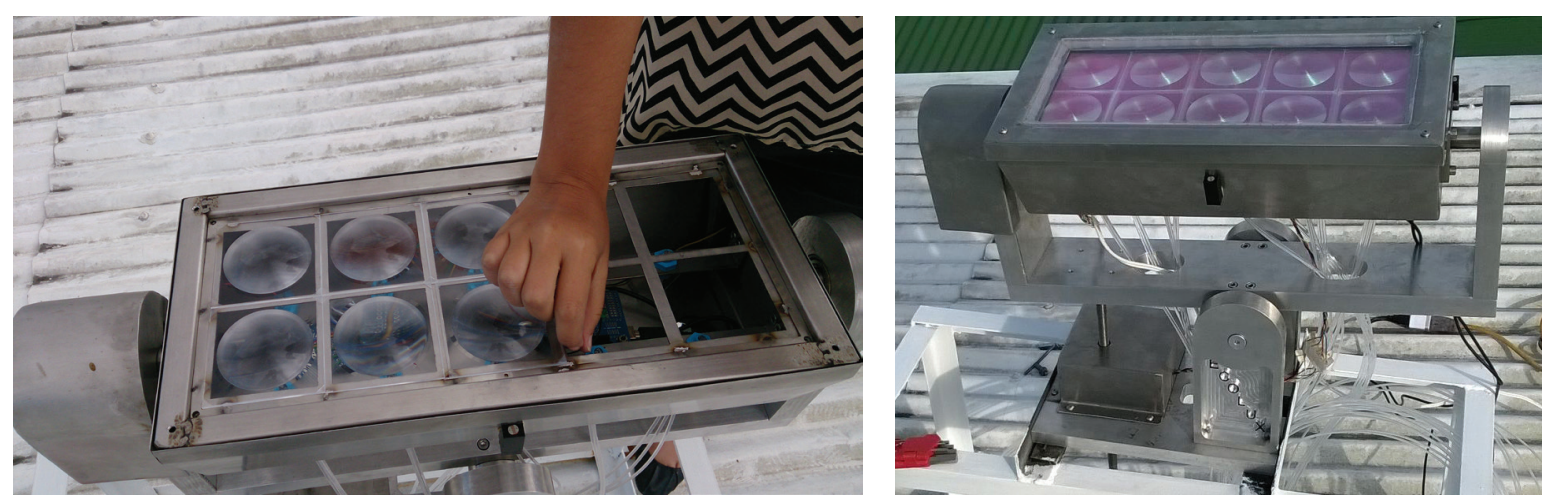

\section{Fibras}

Las fibras son uno de los elementos responsables de modificaciones sustanciales durante la construcción del SINFO. Si bien se tomó en consideración la tolerancia del radio de giro a efectos de su rendimiento óptico, la rigidez propia de la fibra de PMMA en su versión de $3 \mathrm{~mm}$ no pudo ser anticipada en su efecto sobre el funcionamiento 
mecánico del SINFO. En este aspecto, se tomó la decisión de modificar los enjambres originales de tres fibras, por una sola fibra por férula, con lo que se redujo la cantidad total de líneas de conducción a 10, en lugar de las 30 proyectadas originalmente.
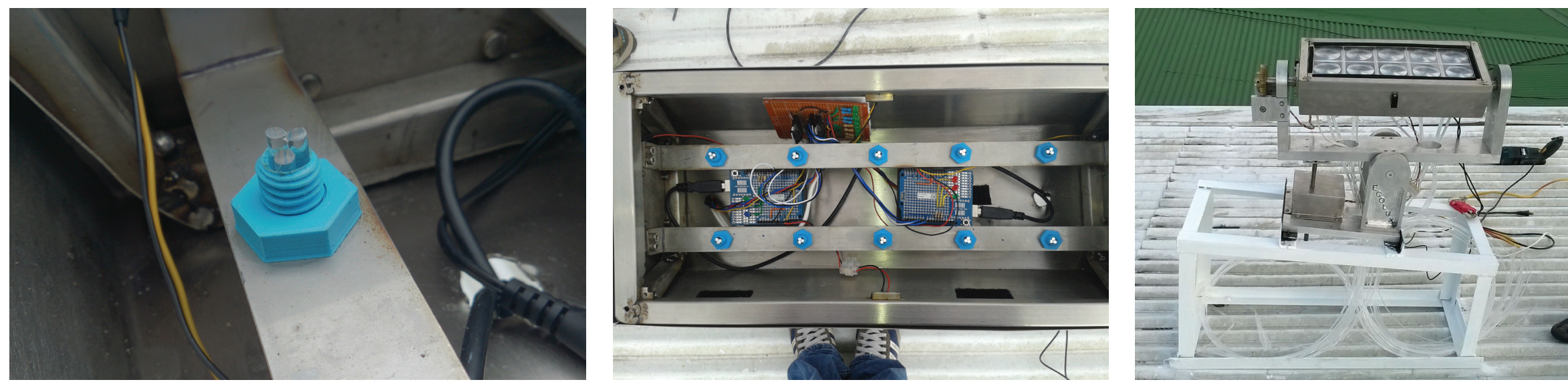

A

Figura 42. Izquierda. Férulas de sujeción de fibras.

Figura 43. Central. Instalación de fibras dentro del SINFO.

Figura 44. Derecha. Ensamble final SINFO.

Figura 45. lluminancia diaria promedio durante el periodo semestral.

\section{Evaluación del rendimiento lumínico del SINFO}

Una vez instalado el SINFO y el sistema de monitorización en el espacio de laboratorio previamente descrito, se recopilaron los datos de iluminancia obtenida en el interior al final del recorrido de las fibras.

\section{Promedios diarios}

Inicialmente, se presentan en la Fig. 45 los valores promedios diarios para todo el periodo semestral de diciembre a mayo. A partir de esta gráfica se interpreta que, así como en la serie de registros de iluminancia externa, también existe una alta varianza entre los datos, sin que esta responda a una tendencia clara según periodos específicos. Además de esto, el rango general en que se agrupan los datos va desde $500 \mathrm{Lx}$ hasta $1500 \mathrm{Lx}$, con algunas excepciones de hasta $2000 \mathrm{Lx}$.

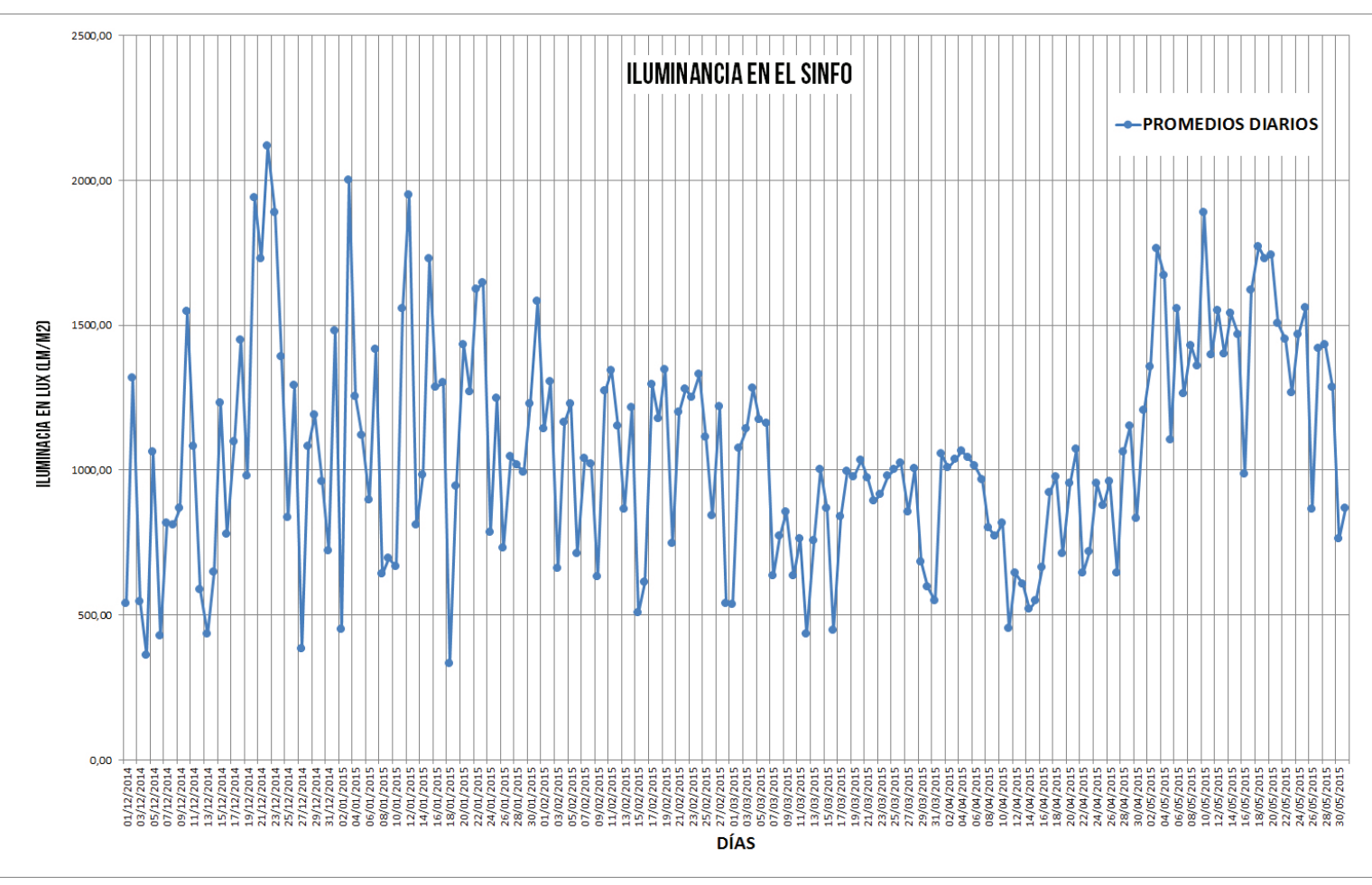

\section{Valores promedio y valores pico}

Resulta muy interesante que la comparación entre valores promedio y los valores pico de cada día enfatiza el carácter inestable de la distribución de los datos. (Ver Fig. 46)

Durante los momentos de mayor rendimiento se registran picos de iluminancia por encima de los $6000 \mathrm{Lx}$, mientras que en los de menor rendimiento los valores máximos diarios caen a cerca de 1500 Lx, muy cercanos a los valores promedio.

Este comportamiento variable e inestable de los datos va en contra de la expectativa de diseño, que buscaba que tuvieran una distribución más uniforme. Entre las principales razones de este comportamiento se encuentran la baja capacidad de aprovechamiento de la iluminación difusa por parte de los lentes Fresnel, la dificultad de seguimiento preciso de la trayectoria solar por la rigidez de la fibra óptica de $3 \mathrm{~mm}$ y el daño al motor del eje horizontal a causa de la contaminación del sistema con ceniza volcánica a lo largo de 2015. 
Figura 46. Sobreposición de valores promedio y pico_SINFO.

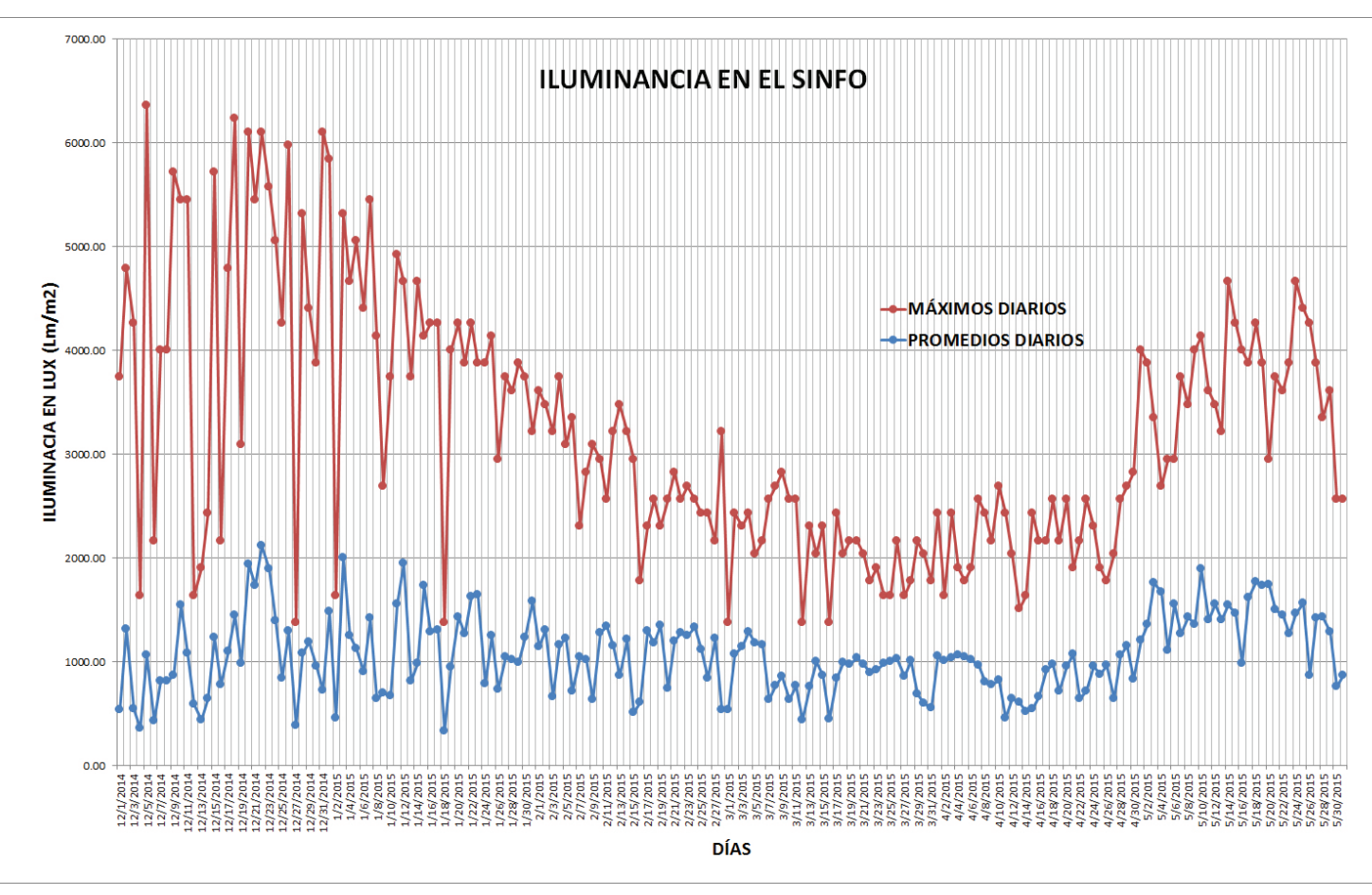

\section{Variación estacional de la iluminancia}

A pesar de lo anterior, existe una tendencia estacional notoria entre el periodo diciembrefebrero y el periodo marzo-abril. Durante el primero, la diferencia entre valores pico y promedio es sumamente alta, con variaciones de hasta 5000 Lx. La Fig.47 muestra un acercamiento al periodo en cuestión.

La desviación estándar (en adelante SD) diaria de este periodo puede apreciarse en el gráfico de la Fig. 48 .

La mayoría de los valores de SD se sitúan entre los 1000 y 1200 puntos, muy por encima de los 420 puntos máximos de la SD para la iluminancia exterior, lo que demuestra una iluminancia interna errática y difícil de predecir.

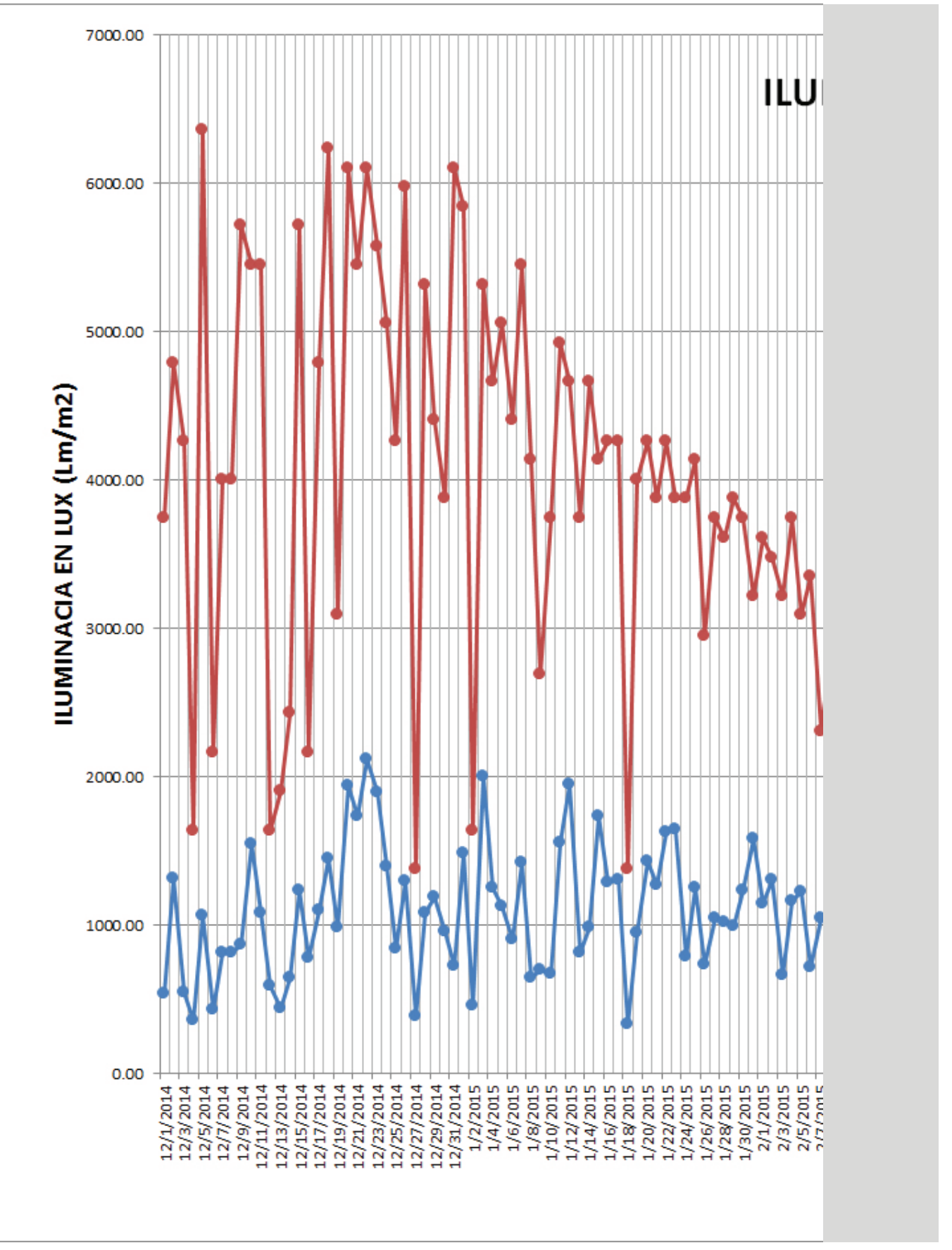


Figura 48. Desviación estándar periodo DiciembreEnero. $>$

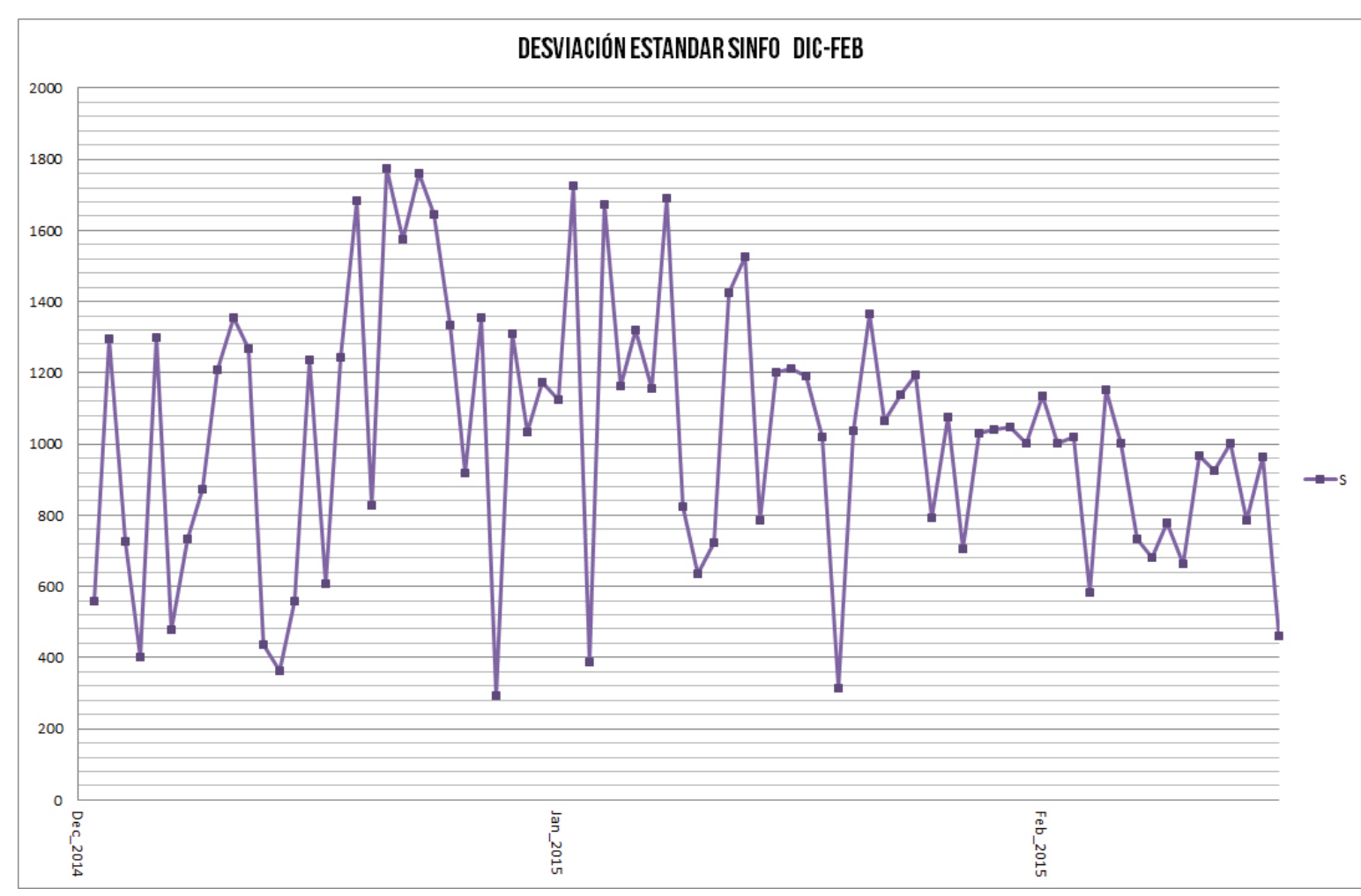

La Fig. 49 muestra un acercamiento al gráfico de rendimiento durante el periodo más estable, comprendido entre el 16 de febrero y el 28 de abril.

La SD diaria correspondiente puede apreciarse en el gráfico de la Fig. 50.

Durante este periodo, la SD desciende a valores muy inferiores, entre los 550 y 800 puntos en promedio, demostrando un comportamiento más estable y predecible.

Finalmente, existe un tercer periodo, determinado entre el 29 de abril y el 1 de junio, durante el cual la variabilidad de los datos vuelve a subir y elevar consigo la SD. Los gráficos de rendimiento y SD para el tercer periodo se muestran a en la Fig. 51 y Fig.52.

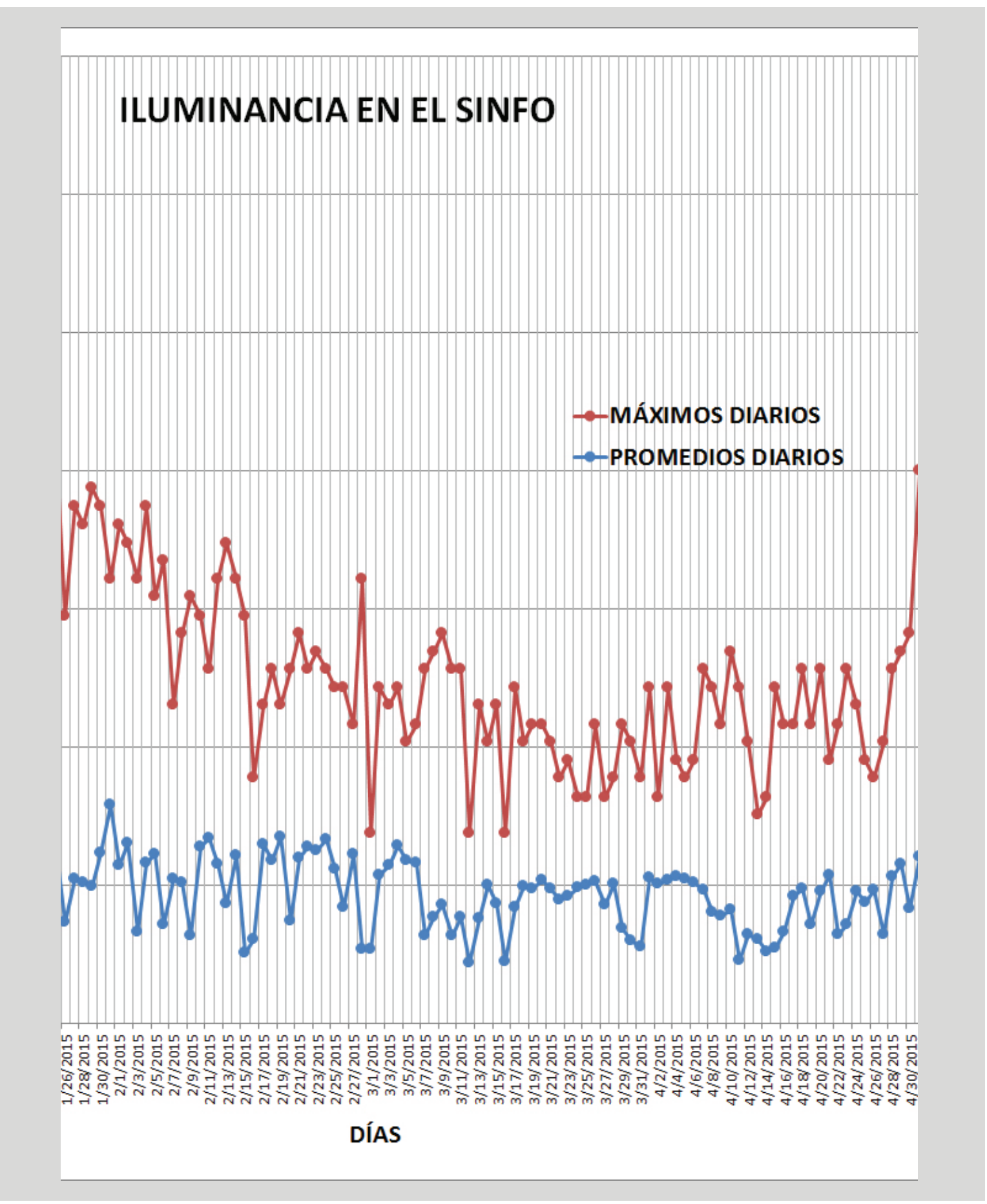



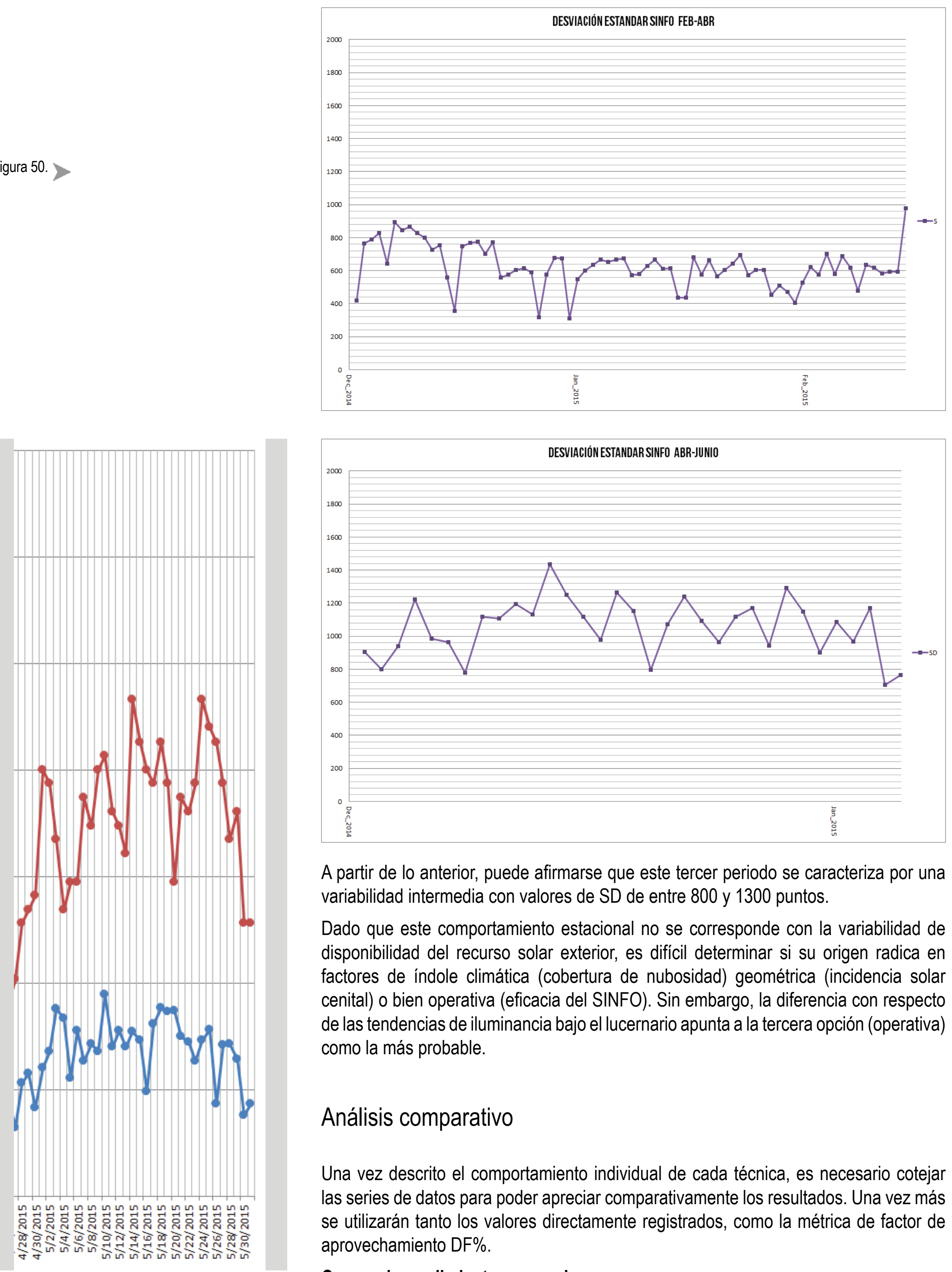

A partir de lo anterior, puede afirmarse que este tercer periodo se caracteriza por una variabilidad intermedia con valores de SD de entre 800 y 1300 puntos.

Dado que este comportamiento estacional no se corresponde con la variabilidad de disponibilidad del recurso solar exterior, es difícil determinar si su origen radica en factores de índole climática (cobertura de nubosidad) geométrica (incidencia solar cenital) o bien operativa (eficacia del SINFO). Sin embargo, la diferencia con respecto de las tendencias de iluminancia bajo el lucernario apunta a la tercera opción (operativa) como la más probable.

\section{Análisis comparativo}

Una vez descrito el comportamiento individual de cada técnica, es necesario cotejar las series de datos para poder apreciar comparativamente los resultados. Una vez más se utilizarán tanto los valores directamente registrados, como la métrica de factor de aprovechamiento DF\%.

\section{Curvas de rendimiento mensual}

Las series se agruparon según su correspondencia con la época seca o lluviosa.

Figura 51. Izquierda. Acercamiento a la fluctuación estacional.

Figura 52. Derecha. Desviación estándar periodo abril-mayo. >

\section{Estación seca}

Las Fig.53, Fig.54, Fig.55 y Fig.56 muestran los gráficos comparativos para los meses de diciembre, enero, febrero y marzo. Resulta de particular interés la cercanía en las líneas de rendimiento durante los meses de diciembre y enero. En este periodo, las 

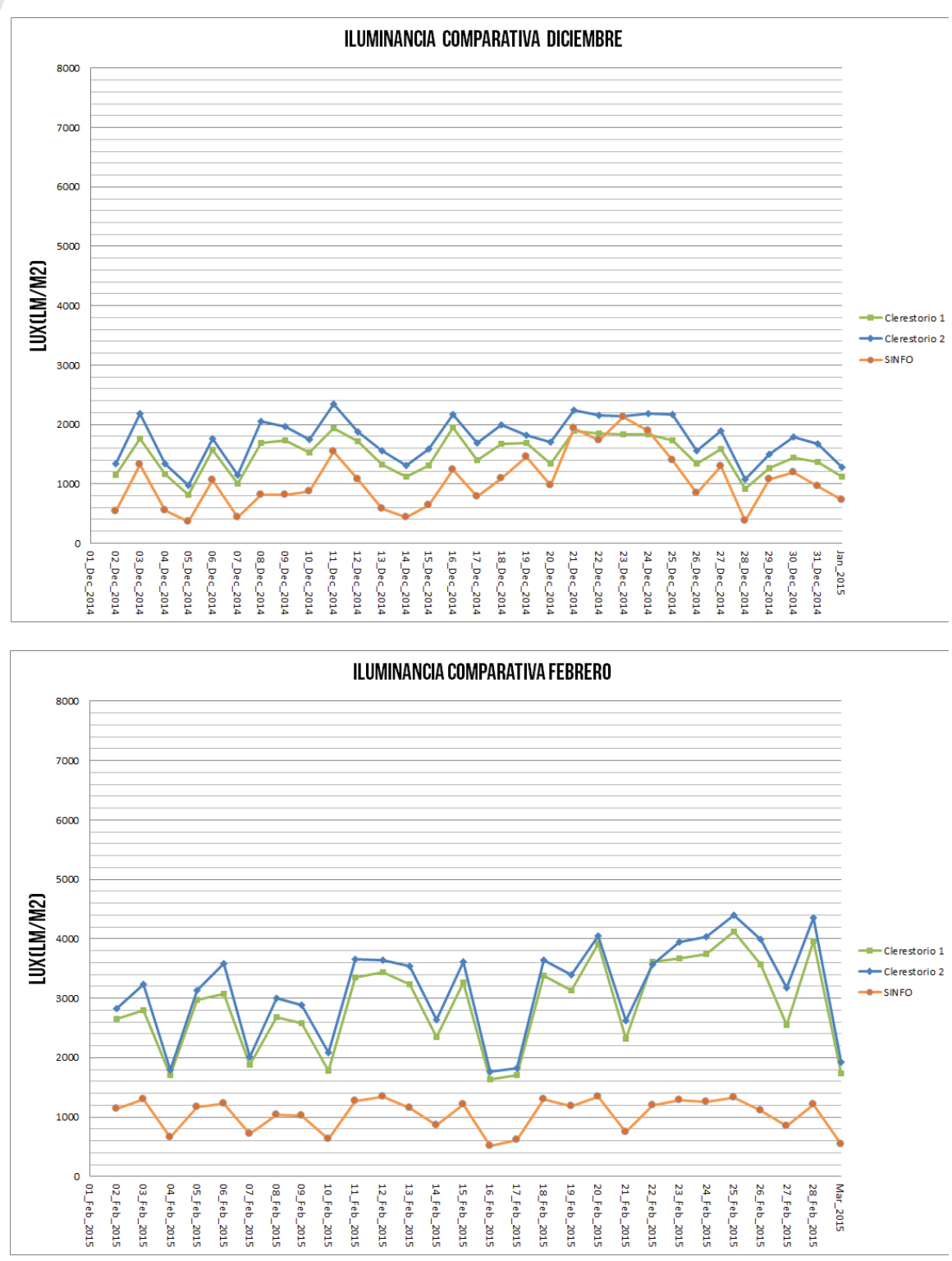
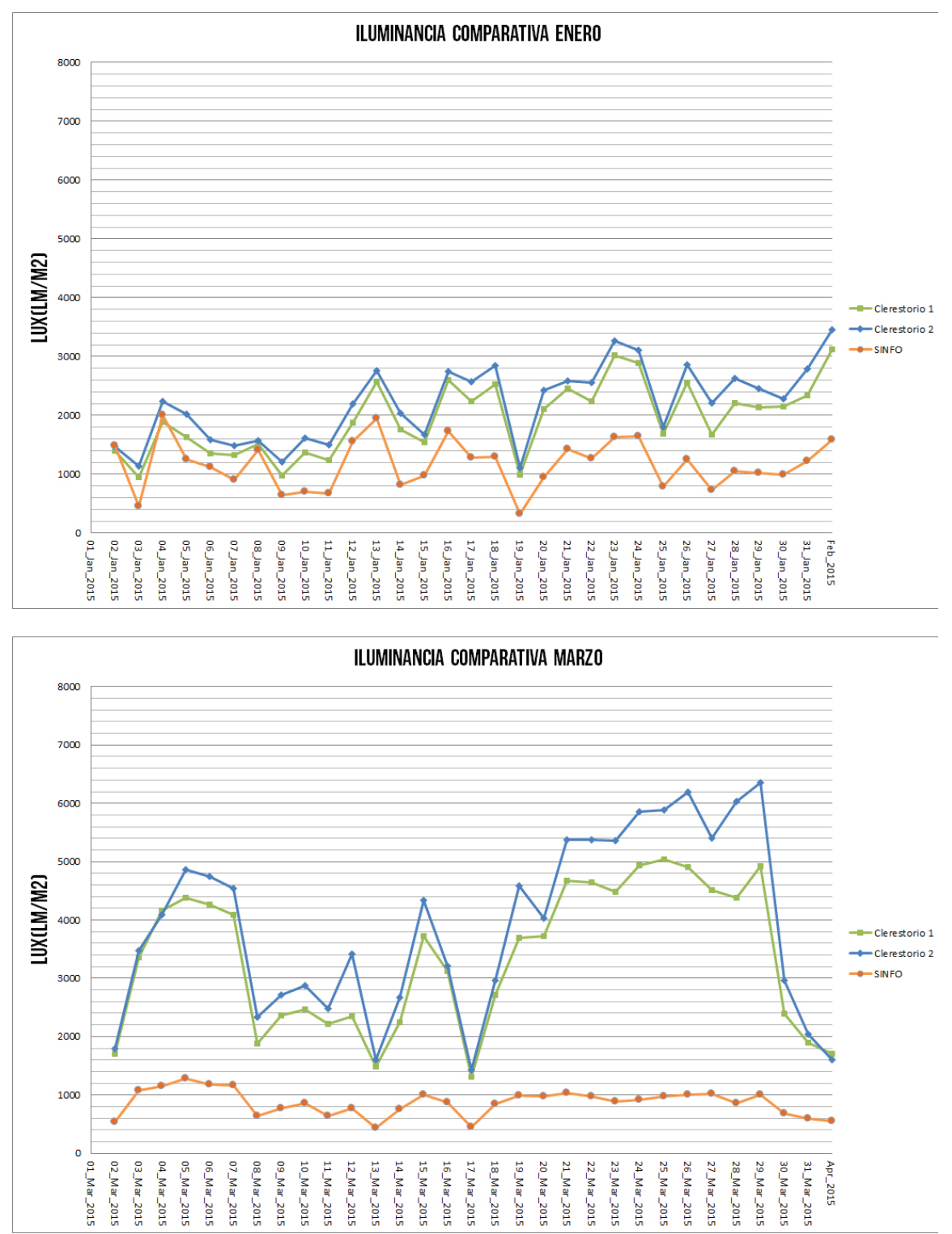

A

Figuras 53, 54, 55 y 56 . Comparación mensual entre valores de iluminancia. diferencias netas entre el lucernario y el SINFO se encuentran en el orden de los 250$500 \mathrm{Lx}$, con tres días específicos durante los cuales el rendimiento promedio de ambas técnicas es equivalente. Posteriormente, a partir del mes de febrero, las diferencias entre las series empiezan a expandirse a una tasa de 1000-2000 Lx por mes.

Este crecimiento en la diferencia de rendimiento presenta dos características; por una parte, es irregular, al igual que la disponibilidad del recurso solar externo, con días específicos donde la amplitud de la diferencia es de tan solo $400 \mathrm{Lx}$. Por otra parte, se da en un periodo climático sin variación significativa de la cobertura nubosa, con lo cual se puede afirmar que el factor responsable del crecimiento de la diferencia de rendimiento es de tipo geométrico y se relaciona directamente con una incidencia solar cenital.

\section{Estación lluviosa}

Durante el periodo siguiente se aprecia un cambio radical en la distribución de los datos, con un incremento sumamente amplio e irregular en la diferencia del rendimiento lumínico. Los gráficos correspondientes a los meses de abril y mayo se muestran en la Fig. 57 y Fig.58 .

En estos meses, el rendimiento del lucernario sufre oscilaciones muy fuertes, con picos cercanos a los $10.000 \mathrm{Lx}$ y valles en el orden de los $2500 \mathrm{Lx}$. Esta tendencia de cambios rápidos refleja una particular susceptibilidad a los cambios bruscos de cobertura nubosa del cielo, típicos de esta época del año. A pesar de ello, los valores reportados por los sensores en el lucernario se encuentran siempre por sobre los valores del SINFO, los cuales, no obstante esa inferioridad, son mucho más regulares y consistentes. En este sentido, resulta aparente que un lucernario de orientación paralela al recorrido solar diario (dirección Este-Oeste) requiere de algún planteamiento de protección externa para la homogenización de los valores de iluminancia interna y la prevención del excesivo ingreso de radiación solar. 

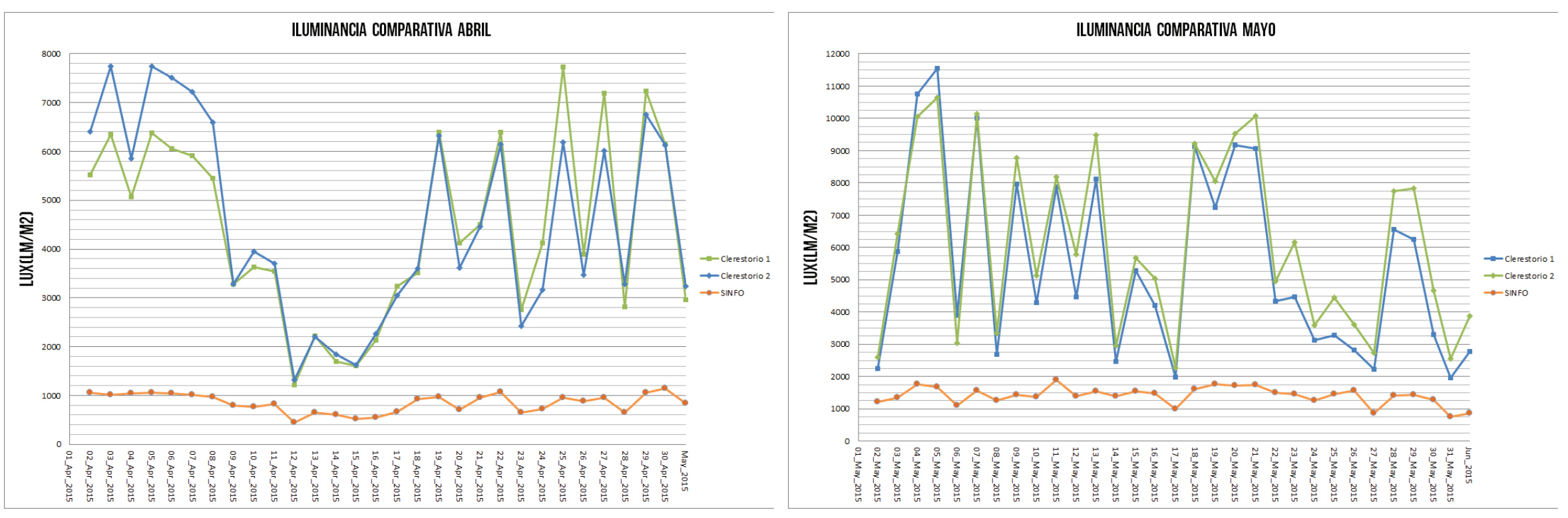

A

Figuras 57 y 58. Comparación mensual entre valores de iluminancia_lluviosa.

Figura 59. Arriba. Comparación semestral entre valores de DF.

Figuras 60 y 61 . Abajo Izquierda y derecha. Comparación trimestral entre valores de DF. Comp

\section{Comparación de Factor de Aprovechamiento (DF\%)}

Con base en las series anteriores, se procedió a calcular el factor de aprovechamiento de luz diurna, DF\%. Los gráficos se presentan en periodos semestrales y trimestrales en la Fig.59, Fig.60 y Fig.61. Al igual que en el caso anterior, las líneas en azul y verde representan el rendimiento del lucernario, mientras que la línea naranja representa el rendimiento del SINFO.

Una visualización semestral contribuye a la comprensión del crecimiento en la diferencia de rendimiento, a medida que se avanza del solsticio de invierno al solsticio de verano. Además de esto, se aprecia un cambio brusco en la uniformidad de la distribución de los datos hacia el final del semestre, desde mediados de abril hasta finales de mayo.

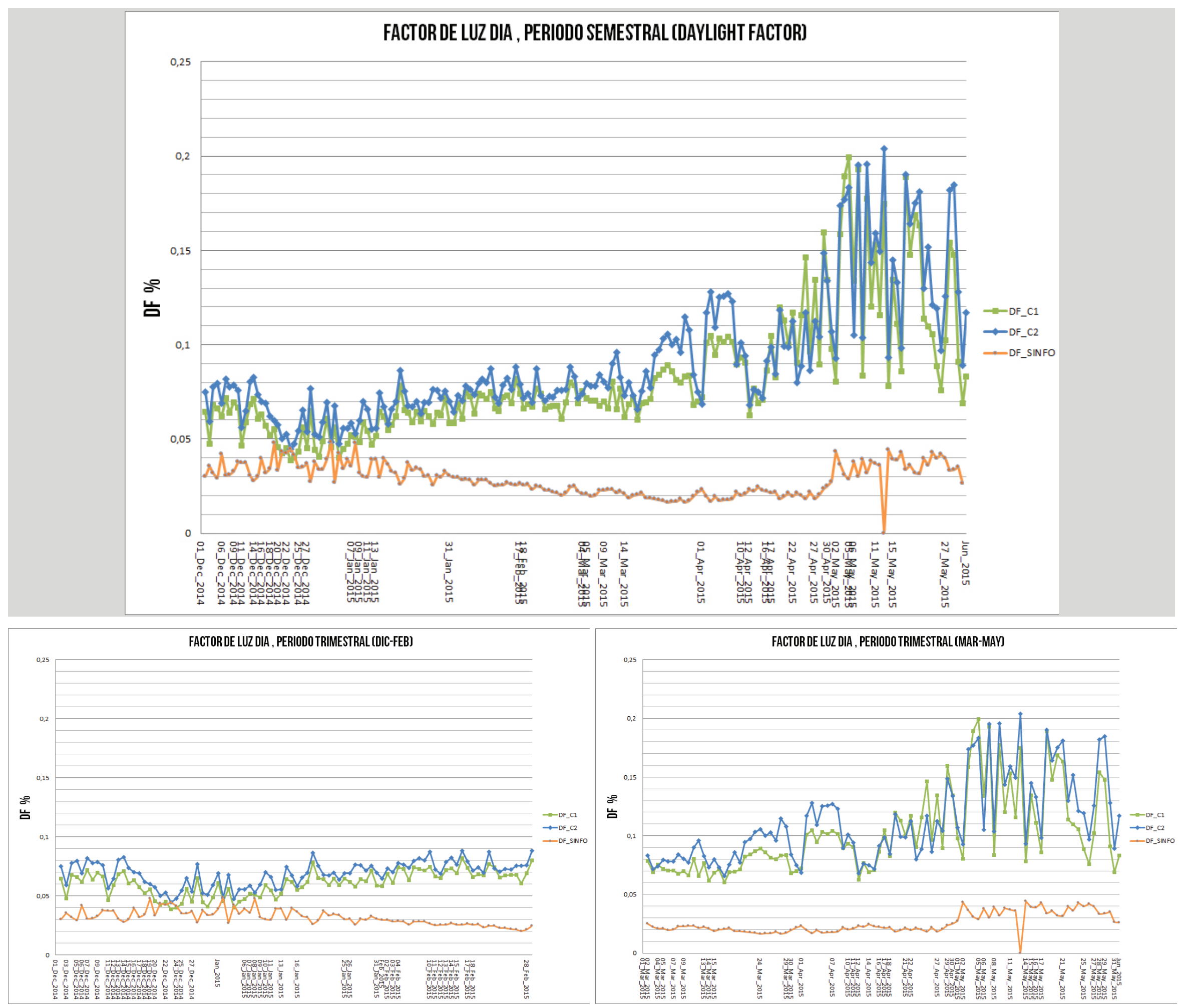


Con una mayor resolución, es evidente que durante el primer trimestre de estudio existe una correlación cercana entre la iluminancia del lucernario y la del SINFO, con coincidencia temporal de picos y valles de cada serie.

En términos de lectura e interpretación, este comportamiento apunta a una combinación de efectos simultáneos. En primer lugar, una irregularidad propia del aumento de la cobertura nubosa principalmente en horas de la tarde. Esta situación climática tiene una implicación directa, disminuyendo la uniformidad de los niveles de iluminancia interna tanto para el SINFO como para el lucernario, pero en mayor medida para el segundo.

En segundo lugar, el efecto de una incidencia solar más directa sobre el espacio interno, es gracias a una posición casi cenital sobre la bóveda celeste. Esta situación es la principal responsable de los elevados picos de rendimiento en el lucernario durante los días despejados. Sin embargo, conlleva un enorme potencial de no confort por el deslumbramiento y/o la acumulación excesiva de carga térmica.

\section{SIMULACIÓN predictiva de rendimiento de lucernarios vía RADIANCE + DAYSIM}

Por una parte, resulta claro que la intensidad de iluminancia resultante en el espacio interno es mucho mayor en el caso del lucernario, principalmente por el mejor aprovechamiento de la radiación difusa. Esto evidencia que la técnica del SINFO requeriría de mucho mayor volumen de producción, a través de más lentes y más fibras, para equiparar el rendimiento del lucernario.

En segunda instancia, se hace necesario emplear una herramienta que permita predecir el comportamiento de la luz dentro del lucernario, en función de eventuales modificaciones sobre sus tres dimensionamientos básicos: área de huella, profundidad y orientación. (Ver figura 62).

Figuras 62. Principales variables de dimensionamiento.

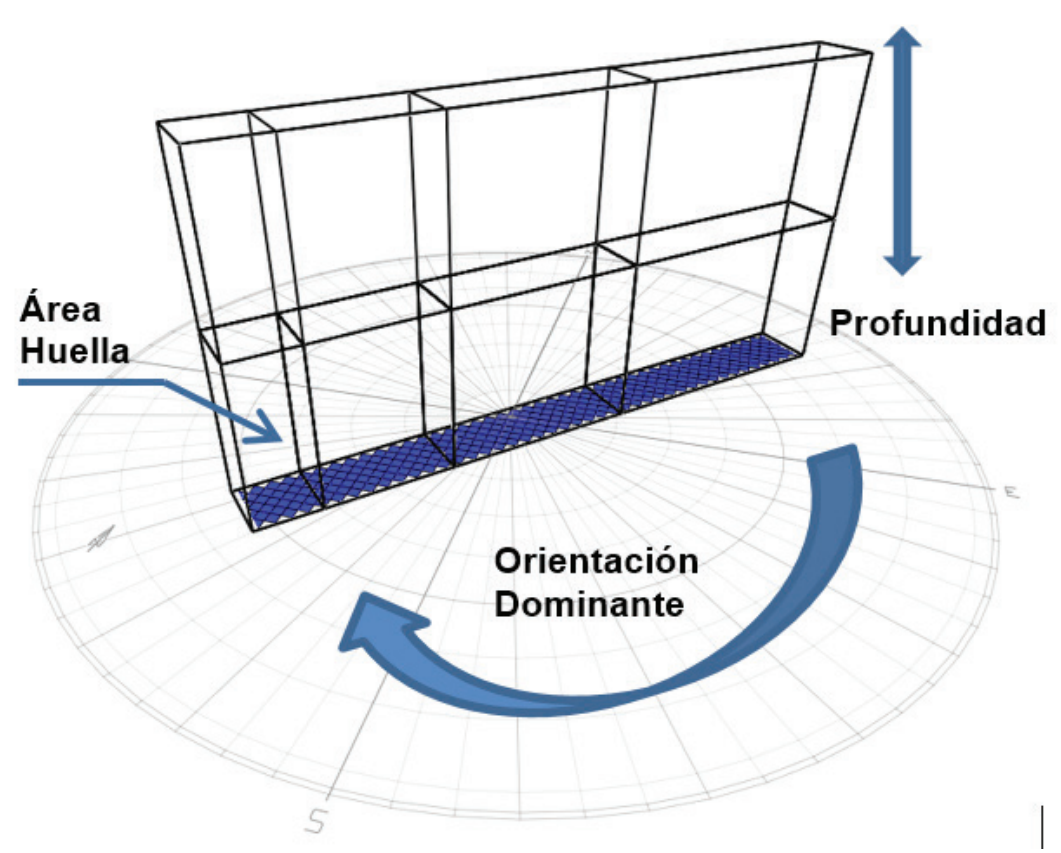

Como se ha mencionado anteriormente, la herramienta de simulación principal elegida es el trazador inverso (backward raytracer) Radiance 4.0, desarrollado por Greg Ward en el Laboratorio Nacional de Lawrence Berkeley (LBNL) California, bajo el patrocinio del Departamento de Energía de Estados Unidos (US DOE) y el Instituto para la Eficiencia Energética de California (CIEE) (Marsh, 2007).

Con base en este modelo, se corrieron múltiples simulaciones de luz incidente (iluminancia), en fechas claves para posteriormente cotejar los resultados obtenidos con los registros reales del sistema de monitorización. Los resultados se estudiaron tanto en visualizaciones bidimensionales (sobre grilla de análisis) como tridimensionales (render de color falso, y líneas de contorno.

Algunas ilustraciones del proceso de calibración se muestran en la Fig. 63, Fig.64, Fig.65 y Fig.66.

Posteriormente a la calibración del motor de cálculo, se procedió a implementar una herramienta de análisis que permite tomar los resultados escalares del paso anterior y combinarlos con la información climática real del sitio, para producir las métricas de rendimiento. 
Figura 63. Izquierda. Modelo analítico en Radiance

Figura 64. Arriba Derecha. Imágenes de la SGC.

Figuras 65 y 66 . Abajo izquierda y derecha. Imágenes de la SGC.
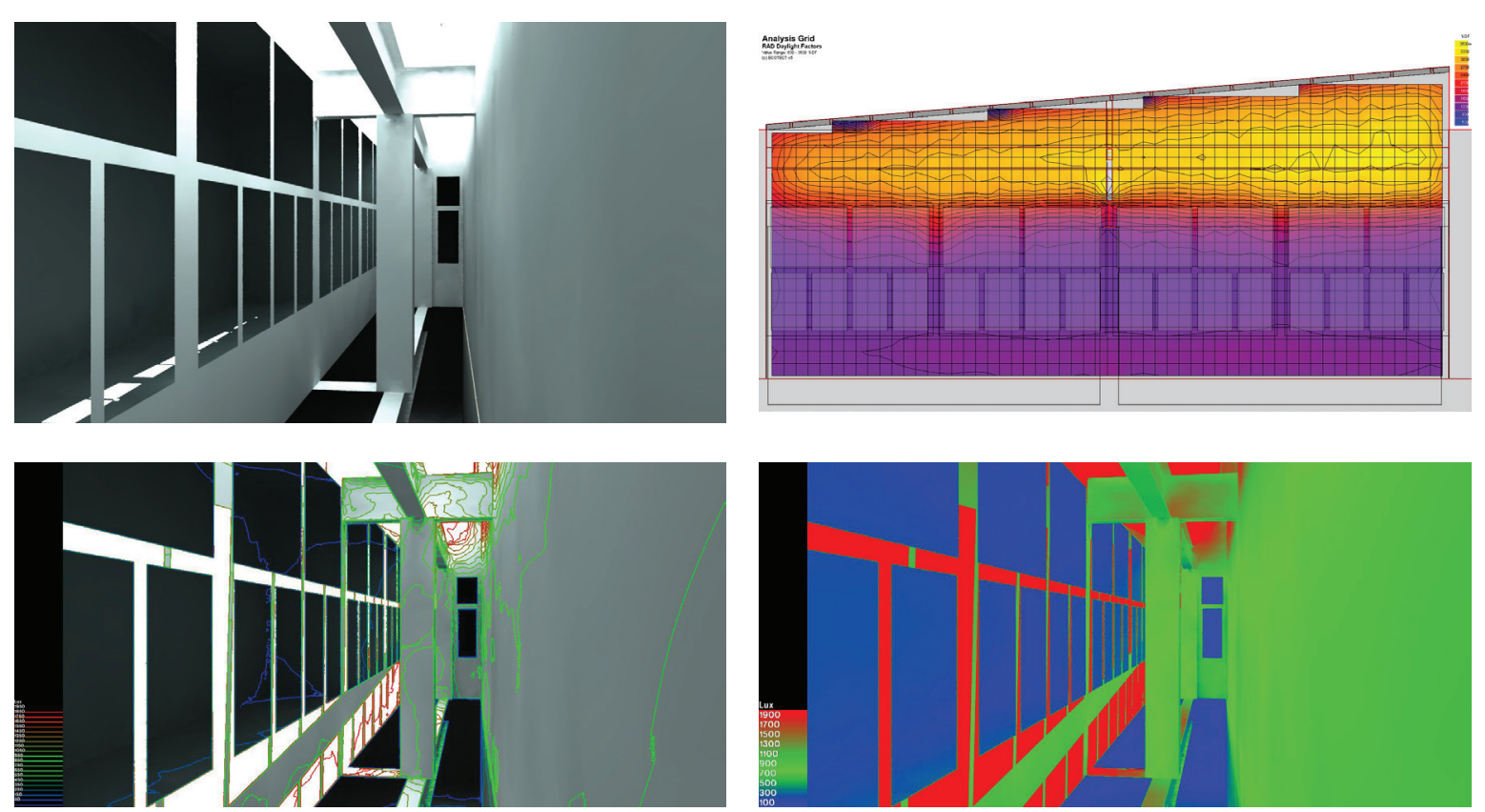

La herramienta seleccionada para este propósito fue DAYSIM 3.1, software de simulación validado basado en clima (climate-based), desarrollado bajo la coordinación del Dr. Reinhart en colaboración con el Instituto Fraunhofer para Sistemas de Energía Solar (ISE), la Universidad de Harvard, el Instituto Tecnológico de Massachusetts (MIT) y el Consejo Nacional de Investigación de Canadá (NRC) (Reinhart, 2010).

DAYSIM es capaz de incorporar variables de comportamiento de usuario, demanda eléctrica por área y registros climáticos, para producir estimaciones de desempeño energético de un sistema lumínico y determinar el cumplimiento de ciertos criterios del sistema de certificación norteamericano LEED (USGBC, 2014).

\section{Proyecciones de rendimiento}

A continuación, se muestran los resultados de simulación de DAYSIM, incorporando la visualización gráfica de las tres métricas en cuestión, así como los seis gráficos de síntesis, con la proyección de rendimiento según las variables descritas anteriormente. En sí, todas las variables han sido consideradas en pares, tanto para la evaluación del rendimiento absoluto (DF\%) con relación al riesgo de sobrecalentamiento (UDI2000), como para la evaluación del rendimiento autónomo (DA400) con relación al potencial de sobrecalentamiento.

Finalmente, estos cruces de variables son agrupados según la orientación predominante del lucernario en planta, sea esta Norte-Sur, Este-Oeste o diagonal a $45^{\circ}$.

La primera secuencia de resultados, correspondiente a la orientación Norte-Sur, se muestra en la Fig.67, Fig.68 y Fig 69 . Los gráficos de rendimiento correspondientes se observan en la Fig. 70 y Fig.71.

La segunda secuencia de resultados, correspondiente a la orientación Este-Oeste, se muestra en la Fig. 72, Fig.73 y Fig.74. Cabe aclarar que cada métrica utiliza una escala con valor máximo independiente, $5 \%$ para el DF $\%, 100 \%$ para el DA400 y $20 \%$ para el UDI2000. Los gráficos de rendimiento para la orientación Este-Oeste se resumen en la Flg.75 y Fig.76.

Finalmente, la tercera secuencia de resultados, correspondiente a la orientación diagonal, se muestra en la Fig. 78 y Fig. 79, junto con los gráficos de proyección de rendimiento de la Fig. 80 y Fig. 81.

\section{Interpretación general de los gráficos}

Todos los gráficos presentados muestran la relación entre los porcentajes esperados para cada parámetro y el aumento progresivo en la distancia desde la cubierta hasta el NPT en estudio. Los porcentajes se encuentran sobre la escala vertical y la profundidad sobre la escala horizontal.

Las distintas series representan las variaciones en la proporción de la huella de cada módulo, desde el cuadrado de 1:1 hasta el rectángulo 1:4. Bajo esta lógica, cada gráfico presenta un total de ocho series con las cuatro posibilidades de huella para dos métricas específicas. 
El estudio de la correlación entre estos "pares" de métricas permite visualizar el aprovechamiento del lucernario con una visión preventiva contra el sobrecalentamiento. En todos los casos se utiliza la línea de guiones para la métrica de rendimiento y la línea sólida para la métrica de riesgo. Los colores son coincidentes para representar la misma proporción de la huella.

\section{Analysis Grid

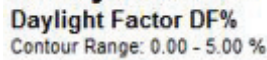 In Steps of $0.50 \%$}

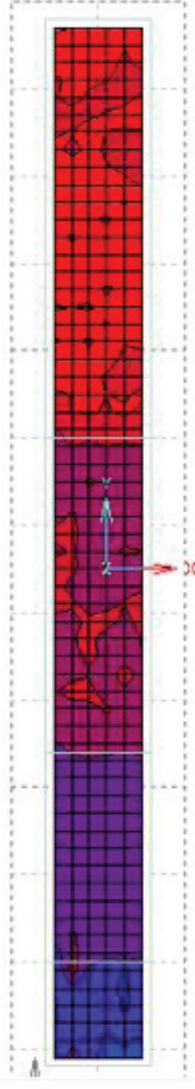

\section{Analysis Grid}

Daylight Autonomy DA400

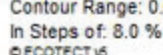

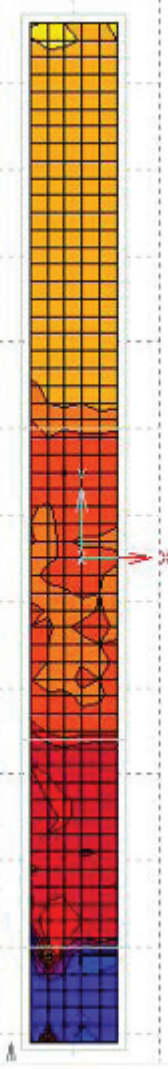

Analysis Grid

Usefull Daylight Illuminance UDI2000

contour Range: $0.0-20.0 \%$

In Steps of. $2.0 \%$
OECOPECT V. 


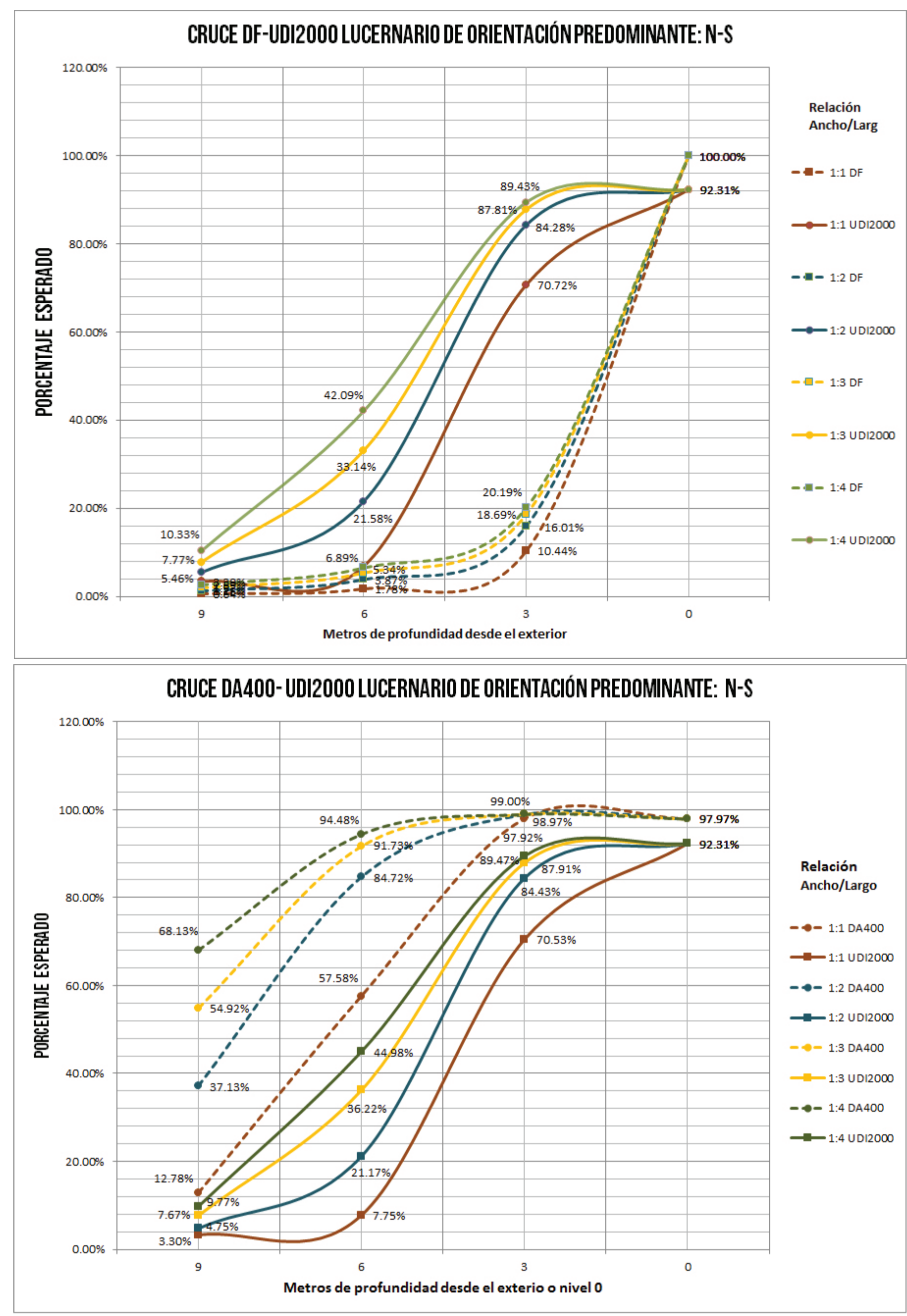

Figuras 70 y 71 . Graficos de proyección de rendimiento N-S.
A Rendimiento del DF\% vs el UDI2000

El primer par de métricas estudiadas corresponde al factor de aprovechamiento de luzdiurna (DF\%) en relación con el riesgo de sobrecalentamiento (UDI2000).

En síntesis, la proporción de huella 1:2 muestra la relación más ventajosa entre rendimiento lumínico y riesgo de sobrecalentamiento, especialmente en profundidades de 3 a $6 \mathrm{~m}$ (1-2 niveles). En segundo lugar se encuentra la huella 1:3, con un rendimiento lumínico elevado y un riesgo de sobrecalentamiento manejable, particularmente en profundidades de 6-9 m (2-3 niveles). En el caso de la proporción 1:1, se descarta por un rendimiento lumínico sumamente bajo (menor al $2 \%$ ), a excepción de una profundidad de $3 \mathrm{~m}$ (un nivel). Finalmente, las huellas de proporción 1:4 o superiores implican un riesgo de sobrecalentamiento sumamente alto, a excepción de profundidades cercanas a los $9 \mathrm{~m}$ (tres niveles) donde, por su alto rendimiento lumínico, parecen ser la mejor opción de diseño. 


\section{Rendimiento del DA400 vs el UDI2000}

Los resultados anteriormente descritos fácilmente se pueden malinterpretar, especialmente por los porcentajes del DF\% siempre por debajo del 20\%. Por esta razón, la métrica del DA400 (autonomía lumínica a 400 Lx) brinda una mejor idea de la autosuficiencia lumínica real de cada espacio.

Figuras 72,73 y 74 . Resultados de simulación Este-Oeste.
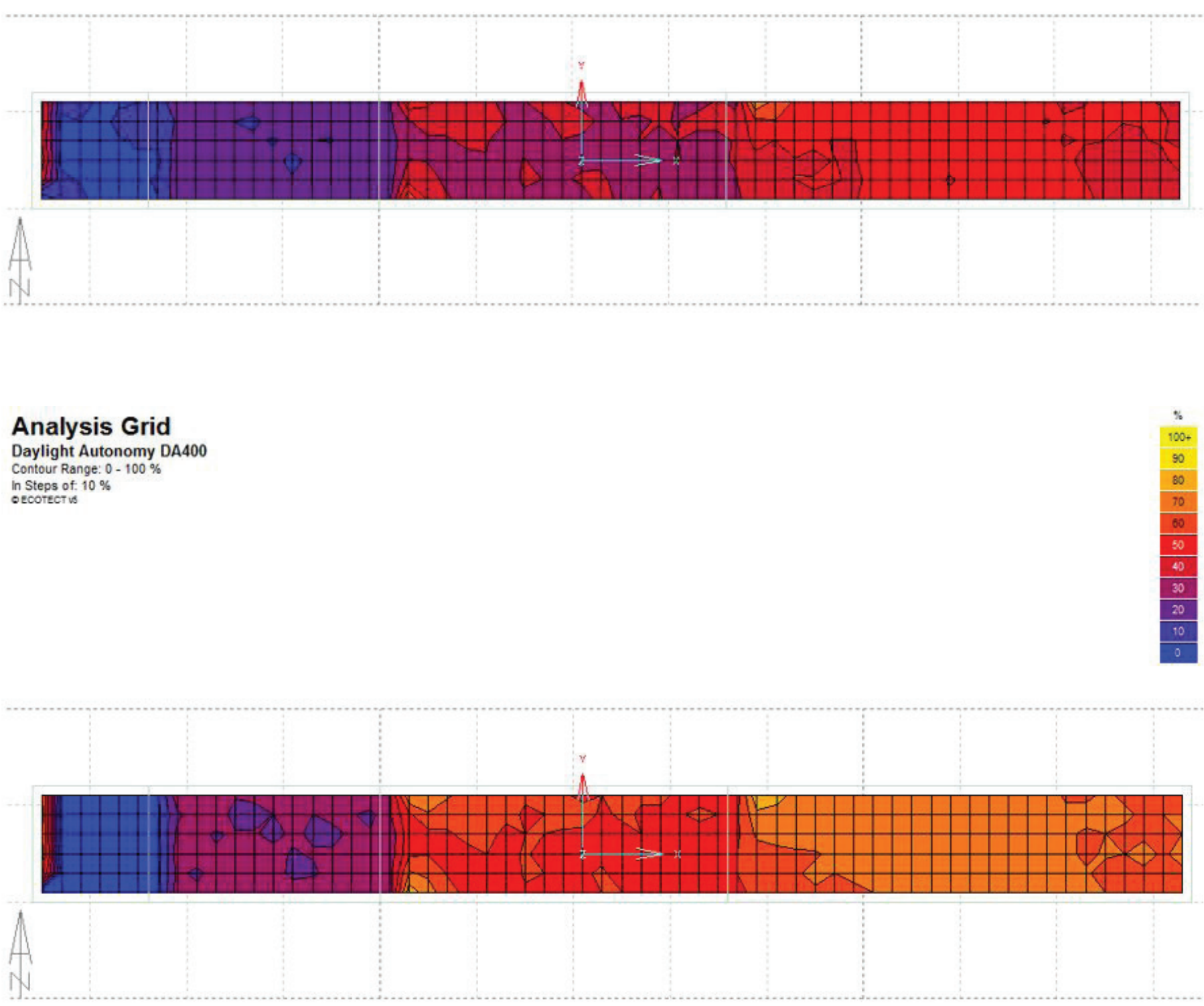

\section{Analysis Grid}

Useful Daylight Illuminance UDI2000

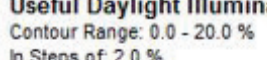

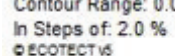

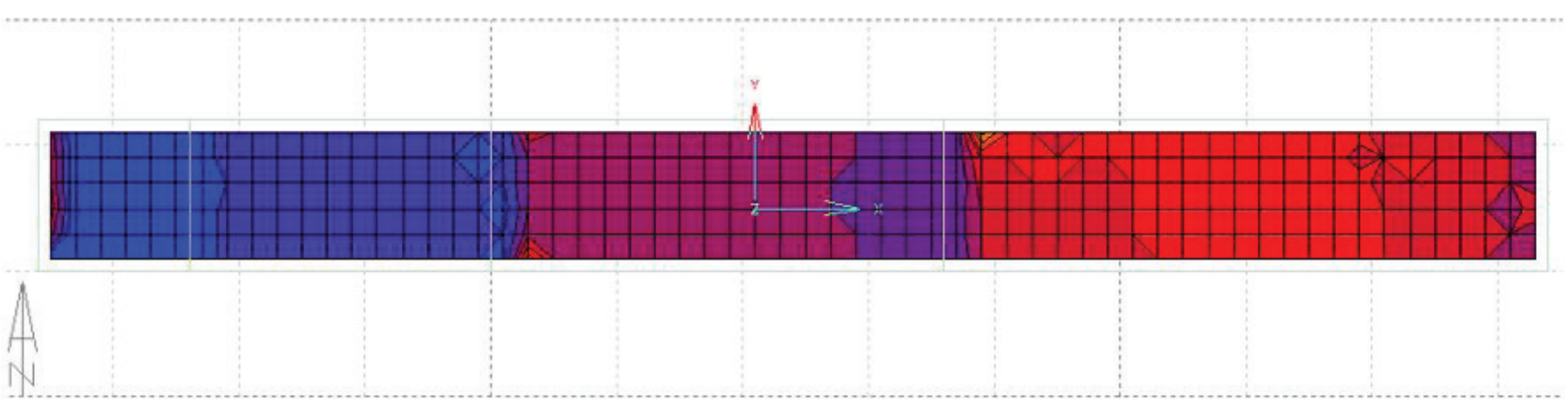



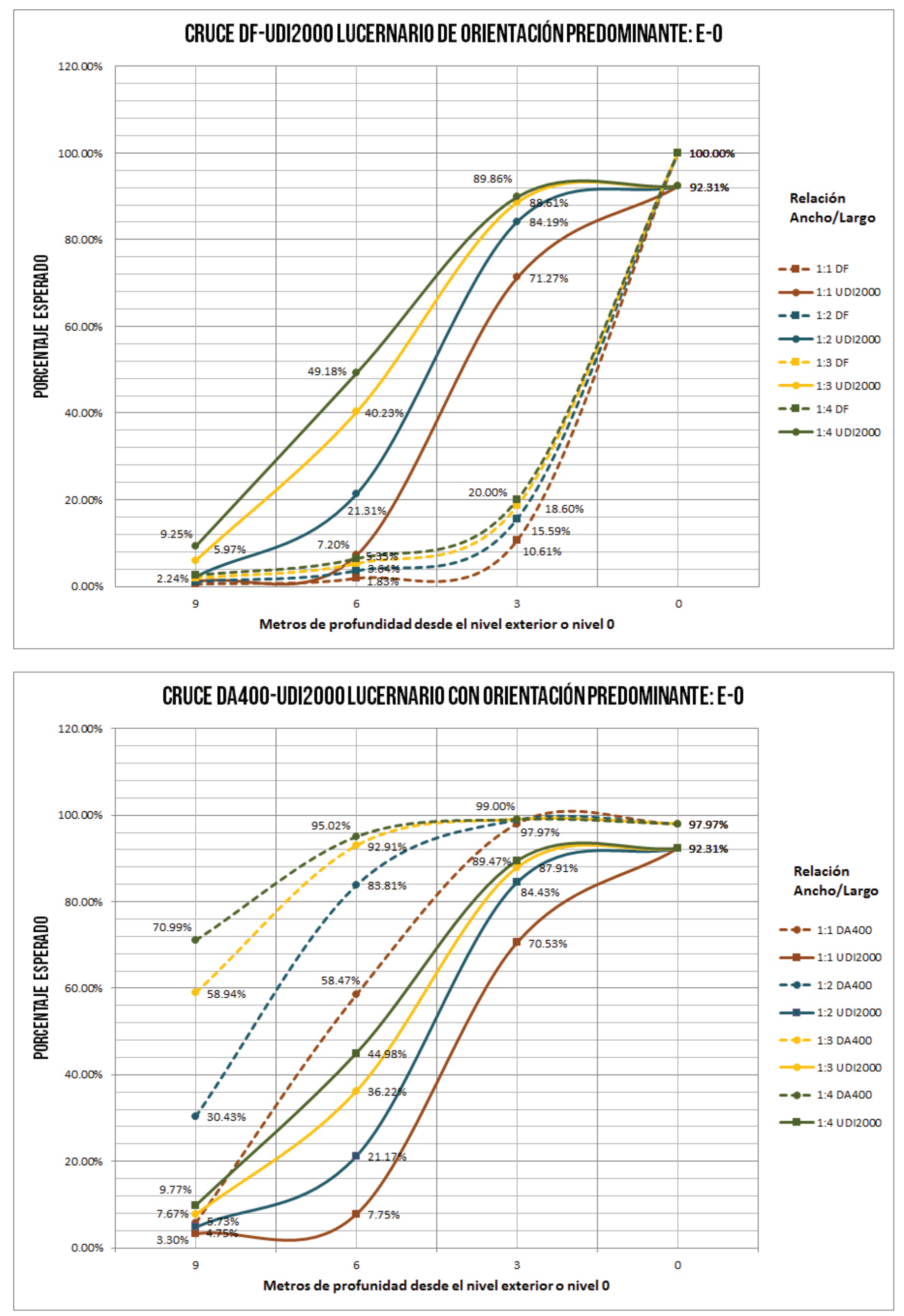

En este caso, las proporciones de 1:3 y 1:4 tienen rendimientos de DA400 sumamente altos, logrando valores superiores al $50 \%$ aún en profundidad de $9 \mathrm{~m}$ (tres niveles), sin embargo, mantienen altas posibilidades de sobrecalentamiento en profundidades de 3 y $6 \mathrm{~m}$. La huella de proporción 1:2 sigue logrando la mejor relación con un mayor balance entre rendimiento y riesgo. Sus valores de DA400 son de $98 \%, 97 \%, 85 \%$, y $40 \%$ para profundidades correspondientes a 3,6, y $9 \mathrm{~m}$. Al mismo tiempo, sus valores de UDI2000 son de $84 \%, 21 \%$ y $5 \%$, respectivamente, lo cual demuestra que es una dimensión de diseño de alto rendimiento a excepción de la profundidad de $3 \mathrm{~m}$. 
Analysis Grid Annual illuminance
Contour Range: $0.00-50.00 \%$ Contour Range: 0.00 -
in Steps 0 of $0.50 \%$
oecoreceris

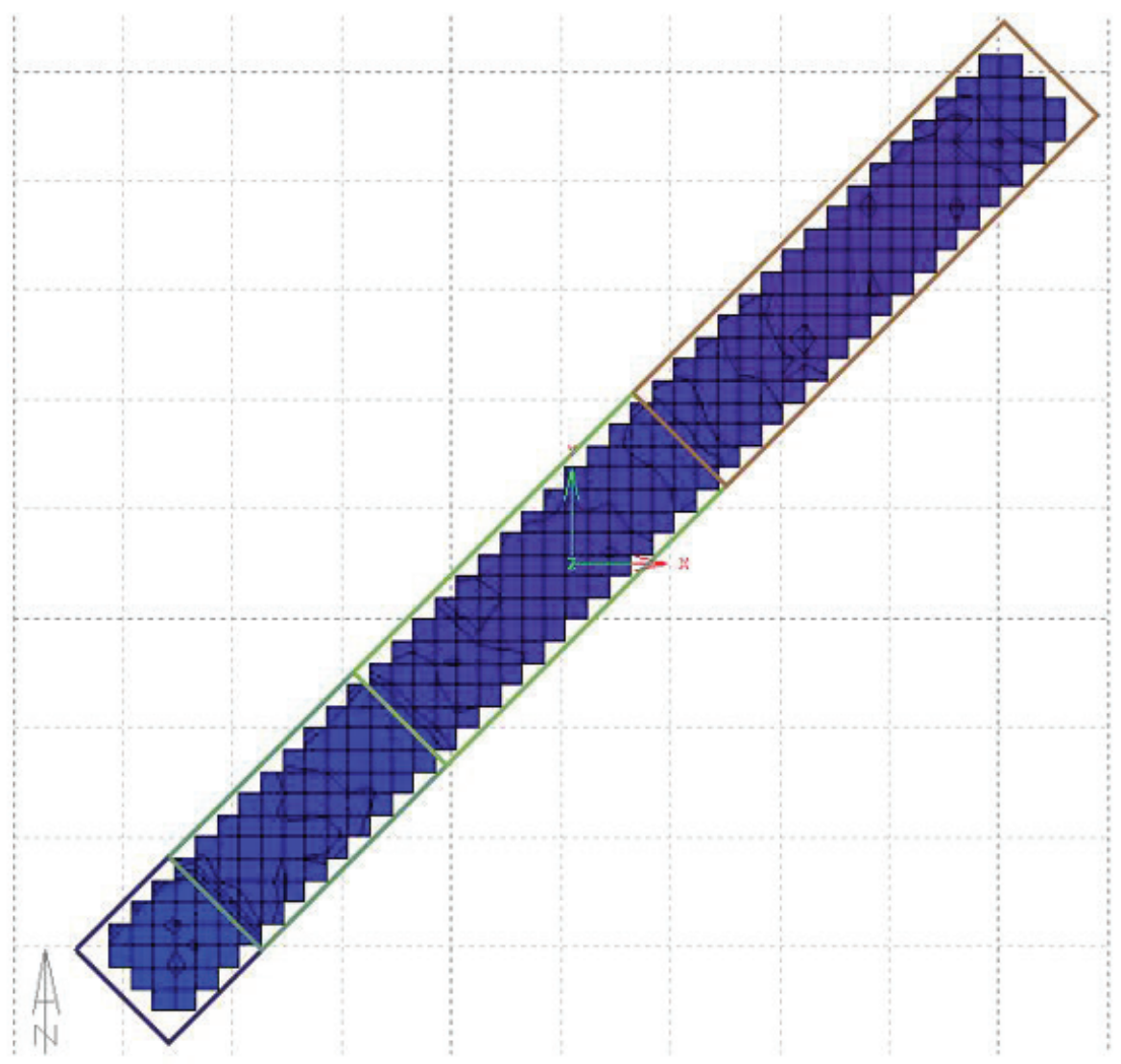

\section{Analysis Grid} Useful Daylight Illuminance Contour Range: $0.0 \%$
In Stips of $2.0 \%$
oecorectis

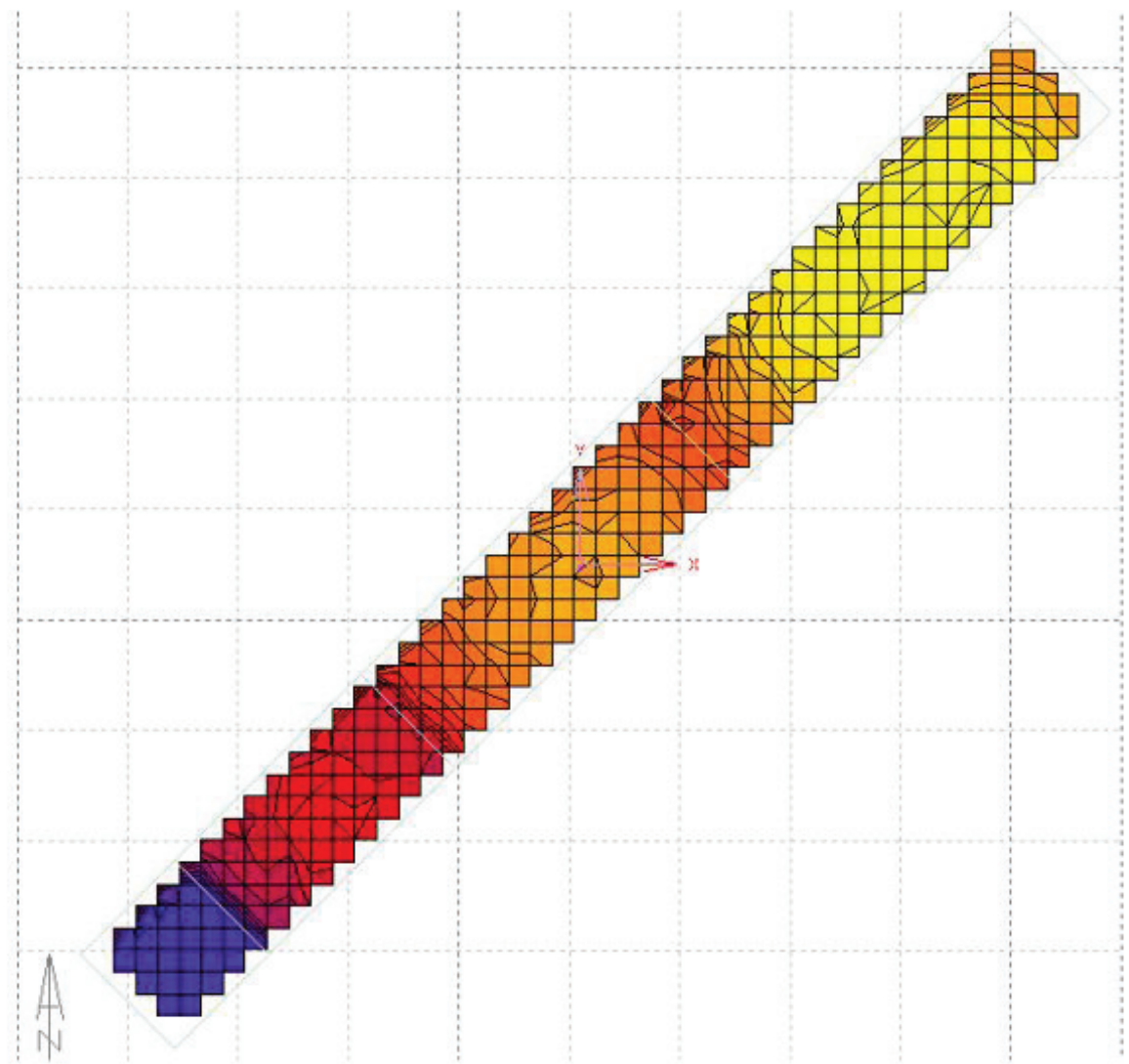

Analysis Grid Daylight Autonomy DA400

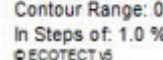

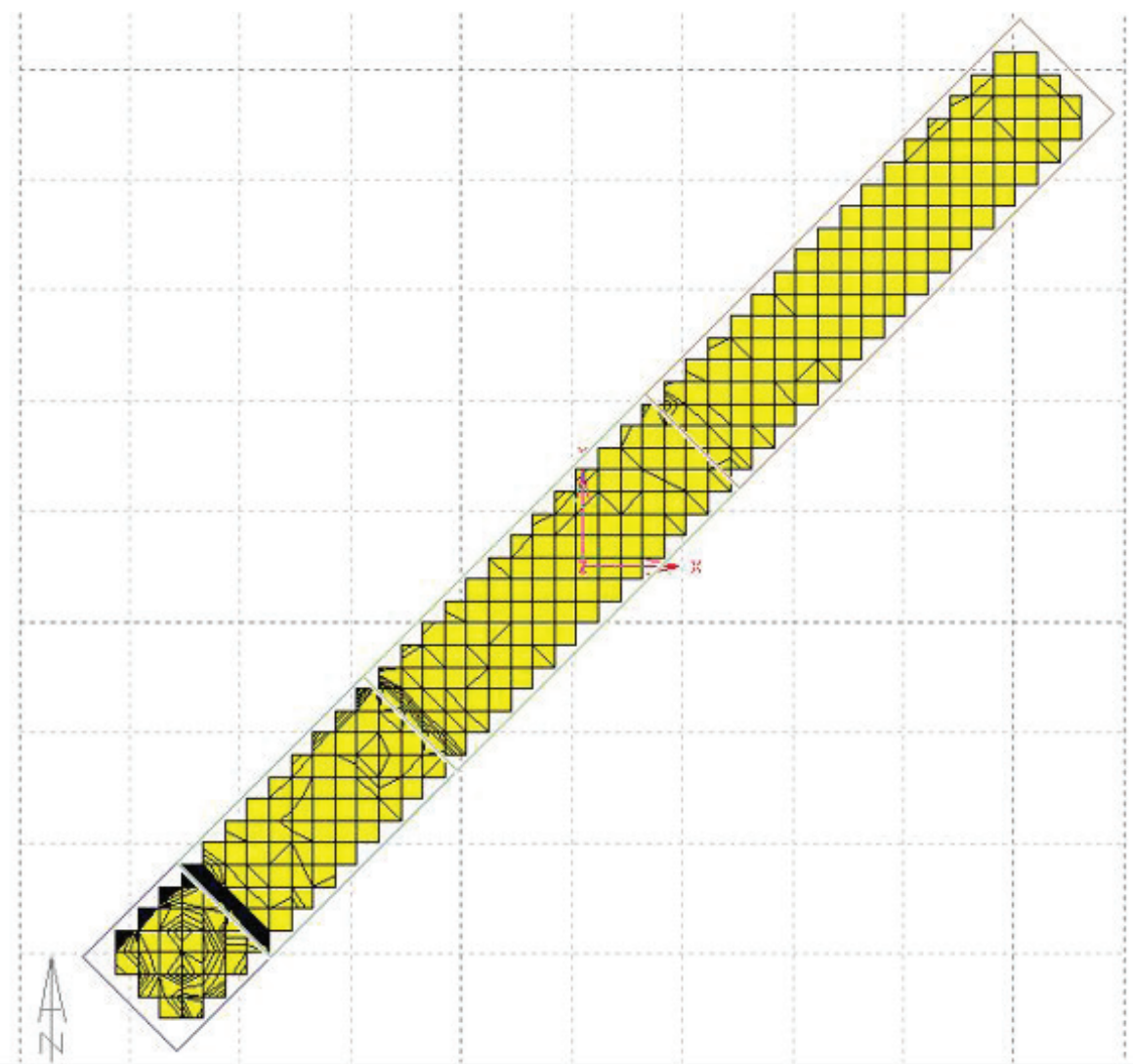



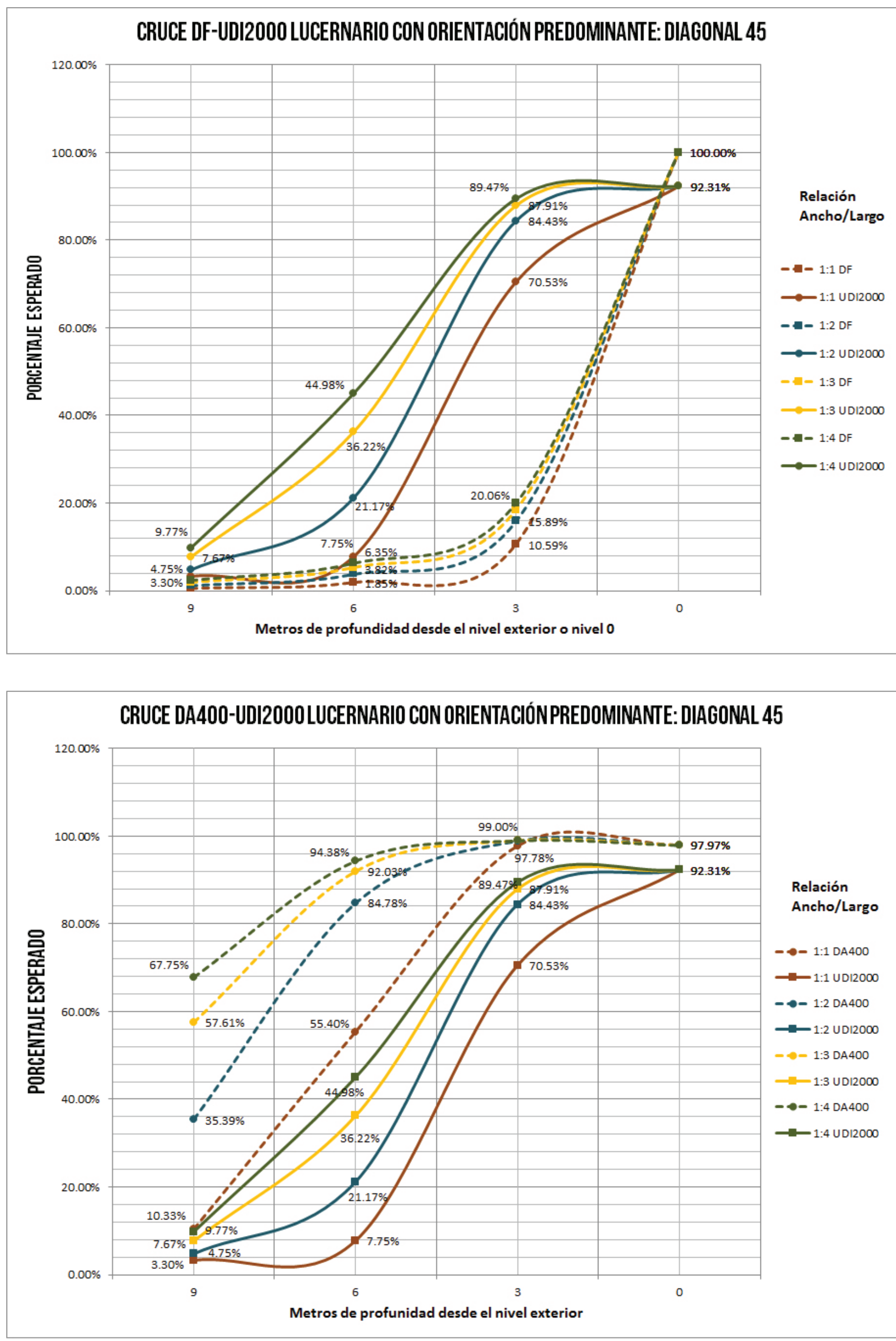


\section{Consideraciones finales y recomendaciones}

De manera resumida, se agrupan a continuación varias conclusiones y recomendaciones según la correspondiente fase de la investigación.

\section{Sobre el aprovechamiento de la radiación solar con fines de iluminación arquitectónica}

- La radiación solar global incidente sobre la superficie terrestre tiene aportes tanto de componente directo como difuso, cuyo aprovechamiento debe hacerse diferenciadamente por parte del diseñador arquitectónico.

- El componente de radiación solar difusa es fácilmente aprovechado por lucernarios de poca profundidad.

- El diseño de lucernarios a más de $9 \mathrm{~m}$ de profundidad (edificios con cuatro o más niveles) requiere del aprovechamiento controlado de la radiación solar directa.

Sobre el diseño de un SINFO para su uso en países situados dentro de la franja tropical

- El rango geométrico de movimiento que un concentrador solar debe cubrir dentro de la franja tropical es sumamente amplio, con ángulos horizontales máximos de $47^{\circ} \mathrm{y}$ verticales máximos de $170^{\circ}$ (Boyce \& Raynham, 2009).

- La cobertura nubosa altamente variable de la franja tropical hace que la disponibilidad de radiación solar directa sea altamente variable con fluctuaciones rápidas. Esto compromete la uniformidad de rendimiento de los lentes Fresnel y de todo el SINFO.

- La radiación solar difusa no es aprovechable a través de los lentes Fresnel, que requieren haces con incidencia directa para concentrar el cono de luz hacia la fibra óptica.

- Los componentes del sistema de movimiento, especialmente la gata mecánica responsable del eje horizontal, debe protegerse más en contra de los agentes externos, tales como polvo, basura, y ceniza volcánica.

- El gran rango de movimiento que se exige al concentrador limita el grosor máximo de la fibra a utilizar, lo que disminuye el rendimiento general del sistema. El uso de más fibras de $3 \mathrm{~mm}$ demanda un sistema de motores más potente $y$, por consiguiente, una mayor demanda energética, lo que contradice el objetivo general del sistema.

Sobre el diseño de un lucernario para su uso en países situados dentro de la franja tropical

- Los patios de luz tradicionalmente utilizados en estas latitudes suelen adaptarse con cubiertas traslúcidas para eliminar el ingreso de precipitación y aprovechar utilitariamente el área bajo ellos, por lo cual es conveniente desde un punto de vista de diseño arquitectónico, considerar el uso de lucernarios cubiertos, desde la etapa inicial.

- Las tres principales variables de diseño para un lucernario son, en orden de importancia, la profundidad (distancia entre cubierta y NPT), la proporción de la huella y su orientación con respecto del azimuth solar.

- Los resultados de las herramientas de simulación computacional Radiance y DAYSIM, a pesar de estar validadas experimentalmente (Reinhart, 2011), requieren de un riguroso proceso de calibración para predecir de manera precisa el rendimiento lumínico en condiciones reales. Por esta razón, su uso es de mucho mayor provecho bajo una lógica de comparación de opciones de diseño, en lugar de una aproximación $100 \%$ precisa del resultado lumínico final.

- En términos de dimensionamiento, el lucernario con proporción de huella 1:1 parece ser el más adecuado para edificios de un nivel de profundidad de aproximadamente $3 \mathrm{~m}$, independientemente de su orientación. La huella de proporción 1:2 es ideal para lucernarios de 3 a 7,5 m de profundidad, con un balance óptimo entre rendimiento lumínico y bajo riesgo de sobrecalentamiento. Al igual que en el caso anterior, su rendimiento es relativamente independiente de la orientación, gracias a un buen aprovechamiento de los rebotes de luz indirecta. 
Las huellas 1:3 y 1:4 presentan características muy similares, con predilección por la 1:3 en lucernarios de hasta $9 \mathrm{~m}$ de profundidad, por lograr un menor riesgo de sobrecalentamiento sin sacrificio sensible de rendimiento lumínico.

- En lucernarios con más de $9 \mathrm{~m}$ de profundidad pueden utilizarse huellas de proporción 1:4 o superiores, con la especial excepción de la orientación Este-Oeste, para la cual el riesgo de sobrecalentamiento se mantiene alto a pesar del crecimiento de la profundidad.

- El factor que hace la diferencia sustancial entre el rendimiento del SINFO y el lucernario es la capacidad para el aprovechamiento de la radiación solar difusa, con una menor carga térmica y una mayor eficacia lumínica $(\mathrm{Im} / \mathrm{W})$ que la radiación solar directa.

\section{Recomendaciones para futuras líneas de investigación}

- Los hallazgos de esta investigación sirven como base, a futuros proyectos que quieran ampliar la gama de escenarios de dimensionamiento y dispositivos de protección externa, específicamente para el trabajo con lucernarios de gran tamaño.

- $\quad$ El uso de herramientas de simulación computacional de alta precisión presentan una curva de aprendizaje considerable, y de alta necesidad iterativa. En este sentido unos de los objetivos clave de proyectos basados en esta tecnología, debe ser el de traducir los resultados de la misma, en guías de diseño fácilmente legibles y comprensibles por los profesionales del gremio.

- $\quad$ El objetivo de la eficiencia energética no puede perderse de vista a medida que se exploran nuevas posibilidades para el aprovechamiento de los recursos naturales. De otra manera, los requerimientos energéticos de las tecnologías propuestas pueden equiparar o hasta superar el ahorro potencial.

\section{Equipo de trabajo del TEC}

EscueladeArquitecturayUrbanismo:profesorGerardoRamírezGonzálezcomolnvestigador Coordinador y profesor Investigador Secundario Sebastián Orozco Muñoz, estudiantes Claudio Jiménez, Vicente Navarro, Isaac García, Bibiana Jiménez y Susan Segovia.

Escuela de Ingeniería en Diseño Industrial: profesor Mario González, estudiantes Melvin Jiménez y Andrés Montero.

Escuela de Ciencias e Ingeniería en Materiales: profesor José Luis León.

Escuela de Ingeniería Electrónica: Área de la Carrera de Mecatrónica, profesora Arys Carrasquilla, estudiantes William Jiménez, Pablo César Rodríguez y Kevin Rodríguez.

\section{Referencias Bibliográficas}

Advanced Daylighting Group. (1999). Technical solid core information. Manuscrito sin publicar.

André, E. \& Schade, J. (2002). Daylighting by optical fiber. Tesis de Maestría (Master of Science Programme, Lulea University of Technology). 2002:260 CIV. ISSN: 14021617.

Apian-Bennewitz, P. (2015). Radiance knowledge database. Obtenido de http://www. radiance-online.org/

Boyce, P. \& Raynham, P. (2009). The SLL lighting handbook. En S. Boreham y P. Hadley (Eds.). 1 ed. Inglaterra: The Society of Light and Lighting. Obtenido de http://www. oneeffect.com/public/Lighting-Standards/s/1\%20handbook\%20INTERNATIONAL.pdf

Chaiwiwatworakul, P. \& Chirarattananon, S. (2013). Luminous efficacies of global and diffuse horizontal irradiances in a tropical region. Renewable Energy, 53, 148-158. doi:10.1016/j.renene.2012.10.059

Colsman-Freyberger, C. (2002). Citation from LTU-EX-02260-SE. Lorrach, Germany: BSR Solar Technologies GmbH. 
J. Remund, \& S.C. Müller. (2011). Solar Radiation and Uncertainty Information of Meteonorm 7. PVSEC, Suiza.

Lam, J.C. \& Li, D.H.W. (1996). Luminous efficacy of daylight under different sky conditions. Energy Conversion and Management, 37(12), 1703-1711. doi:10.1016/01968904(96)00021-0

Marsh, A.J. (2007). RADIANCE and daylight factors. Natural Frecuency, 1(004) doi:http:// naturalfrequency.com/articles/radiancedf

Miller, J.V. \& Miller, R.E. (2006). Museum lighitng, pure and simple. En M. Miller (Ed.). 1 ed. Seaford, Delaware: NoUVIR Research. doi: http://www.nouvir.com/pdfs/ MuseumLighting.pdf

Miller, M. Comunicación personal. (2013). Traducción de S. Orozco (Ed.). Massachusets, USA: NoUVIR Lighting.

Nabil, A. \& Mardaljevic, J. (2005). Useful daylight illuminance: A new paradigm to access daylight in buildings. [lluminancia natural útil: Un nuevo paradigma para el acceso de luz natural en edificios]. Lighting Research \& Technology, 1(37), 41-59.

Palmer, J.M. \& Grant, B.G. (2009). Art of radiometry SPIE. Obtenido de http://app. knovel.com/hotlink/toc/id:kpAR000006/art-of-radiometry/art-of-radiometry

Reinhart, C.F. (2010). Tutorial on the use of Daysim simulations for sustainable design. 1 ed. Cambridge, MA, EE.UU.: Graduate School of Design, Harvard University.

Reinhart, C.F. (2011). Simulation-based daylight performance predictions. En J. Hensen y R. Lamberts (Eds.), Building performance simulation for design and operation [Predicciones de rendimiento de iluminación natural, basadas en simulación]. Trad. de S. Orozco. 1 ed. Boston, EE.UU.: Taylor \& Francis.

Rothwell, S. Comunicación Personal, (2013). Escondido, CA, EE.UU. Sunlight Direct: Senior Systems Engineer.

Ryer, A.D. (1997). Light measurement handbook . En Technical Publications Dept. (Ed.). 2 ed. Newburyport, MA, EE.UU.: International Light Inc. doi: http://www.dfisica. ubi.pt/ hgil/fotometria/HandBook/Light-Measurement.1.pdf

Schott, A. (2002). Technical specifications - schott fiber optics. Manuscrito sin publicar.

USGBC (United States Green Building Council). (2014). LEED V4 user guide. En R. Fedrizzi (Ed.). 4 ed. Washington, DC. doi: https://kapost-files prod.s3.amazonaws. com/published/54886ef033efbe406e00012a/ebook-leed-v4-user-guide.pdf 